\title{
The Role of Industry, Geography and Firm Heterogeneity in Credit Risk Diversification
}

\author{
M. Hashem Pesaran, Til Schuermann \\ and Björn-Jakob Treutler
}

May 2005

CWPE 0529

Not to be quoted without permission 


\title{
The Role of Industry, Geography and Firm Heterogeneity in Credit Risk Diversification*
}

\author{
M. Hashem Pesaran \\ University of Cambridge and \\ University of Southern California \\ mhp1@econ.cam.ac.uk
}

\author{
Til Schuermann ${ }^{\dagger}$ \\ Federal Reserve Bank of New York and \\ Wharton Financial Institutions Center \\ til.schuermann@ny.frb.org
}

\author{
Björn-Jakob Treutler \\ Mercer Oliver Wyman \\ btreutler@mow.com
}

May 2005

\begin{abstract}
In theory the potential for credit risk diversification for banks could be substantial. Portfolios are large enough that idiosyncratic risk is diversified away leaving exposure to systematic risk. The potential for portfolio diversification is driven broadly by two characteristics: the degree to which systematic risk factors are correlated with each other and the degree of dependence individual firms have to the different types of risk factors. We propose a model for exploring these dimensions of credit risk diversification: across industry sectors and across different countries or regions. We find that full firm-level parameter heterogeneity matters a great deal for capturing differences in simulated credit loss distributions. Imposing homogeneity results in overly skewed and fat-tailed loss distributions. These differences become more pronounced in the presence of systematic risk factor shocks: increased parameter heterogeneity greatly reduces shock sensitivity. Allowing for regional parameter heterogeneity seems to better approximate the loss distributions generated by the fully heterogeneous model than allowing just for industry heterogeneity. The regional model also exhibits less shock sensitivity.

Key Words: Risk management, default dependence, economic interlinkages, portfolio choice

JEL Classifications: C32, E17, G20
\end{abstract}

\footnotetext{
${ }^{*}$ We would like to thank participants at the NBER Conference on Risk of Financial Institutions, October 2004, and our discussant Richard Cantor for helpful and insightful comments. We would also like to thank Yue Chen and Sam Hanson for their excellent research assistance.

${ }^{\dagger}$ Corresponding author. Any views expressed represent those of the author only and not necessarily those of the Federal Reserve Bank of New York or the Federal Reserve System.

${ }^{\ddagger}$ Any views expressed represent those of the author only and not necessarily those of Mercer Oliver Wyman.
} 


\section{Introduction}

In theory the potential for credit risk diversification for banks can be considerable. Insofar as different industries or sectors are more or less pro-cyclical, banks can alter their lending policy and capital allocation across those sectors. Similarly, internationally active banks are able to apply analogous changes across countries. In addition to such passive credit portfolio management, financial engineering, using instruments such as credit derivatives, enable banks (and other financial institutions) to engage in active credit portfolio management by buying and selling credit risk (or credit protection) across sectors and countries. Credit exposure to the U.S. chemical industry, say, can be traded for credit exposure to the Korean steel sector. One may, therefore, think of a global market for credit exposures where credit risk can be exported and imported.

Within such a global context, default probabilities are driven primarily by how firms are tied to fundamental risk factors, both domestic and foreign, and how those factors are linked across countries. In order to implement such a global approach in the analysis of credit risk, we have developed in Pesaran, Schuermann and Weiner (2004), hereafter PSW, a global vector autoregressive macroeconometric model (GVAR) for a set of 25 countries accounting for about $80 \%$ of world output. Importantly, the foreign variables in the GVAR are tailored to match the international trade pattern of the country under consideration.

Pesaran, Schuermann, Treutler and Weiner (2005), hereafter PSTW, relate asset returns for a portfolio of 119 firms to the global macroeconometric model, thus isolating macro effects from idiosyncratic shocks as they relate to default (and hence loss). The GVAR effectively serves as the macroeconomic engine capturing the economic environment faced by an internationally active global bank. Domestic and foreign macroeconomic variables are allowed to impact each firm differently. In this way we are able to account for firm-specific heterogeneity in an explicitly interdependent global context. Developing such a conditional modeling framework is particularly important for the analysis of the effects of different types of shock scenarios on credit risk, an important feature we exploit here.

In this paper we extend the analysis of PSTW along four dimensions. First, we provide some analytical results on the limits of credit risk diversification. Second, we illustrate the impact of two different identification restrictions regarding the default condition on the resulting loss distributions. Third, we use this framework to understand the degree of diversification with five models which differ in their degree of parameter heterogeneity, from fully homogeneous to allowing for industry and regional heterogeneity but homogeneous factor sensitivities all the way to a fully heterogeneous model. Fourth, we have more than doubled the number of firms in the portfolio from 119 to 243 firms providing for more robust results and allowing us to explore the importance of exposure granularity. We go on to explore the impact of shocks to real equity prices, interest rates and real output on the resulting loss distribution as implied by the different model specifications. 
Such conditional analysis using shock scenarios from observable risk factors is not possible in the most commonly used model in the credit risk literature, namely the Vasicek (1987, 1991, 2002) adaptation of the Merton (1974) default model. In addition to being driven by a single and unobserved risk factor, this model also assumes that risk factor sensitivities, analogous to CAPMstyle betas, are the same across all firms in all regions and industries, yielding a fully homogeneous model. This single factor model also underlies the risk-based capital standards in the New Basel Accord (BCBS (2004)), as shown in Gordy (2003).

We find that full firm-level parameter heterogeneity matters a great deal for capturing differences in simulated credit loss distributions. Imposing homogeneity results in extremely skewed and fat-tailed loss distributions. These differences become more pronounced in the presence of systematic risk factor shocks: increased parameter heterogeneity greatly reduces shock sensitivity. For example, an adverse $2.33 \sigma$ shock to U.S. equity prices increases loss volatility by about $31 \%$ for the fully heterogeneous model, but by $73 \%$ for the homogeneous pooled model. These differences become even more pronounced as shocks become more extreme: for an adverse $5 \sigma$ shock to U.S. equity prices, loss volatility increases by about $85 \%$ for the heterogeneous model, but by more than $240 \%$ for the restricted model.

We further find that symmetric shocks result in asymmetric and nonproportional loss outcomes due to the nonlinearity of the default model. Loss increases arising from adverse shocks are larger than corresponding loss decreases from benign (but equiprobable) shocks. Here too there are important differences across model heterogeneity. While all models exhibit this asymmetry for expected losses and loss volatility, only the fully heterogeneous model maintains this asymmetric response in the tail of the loss distribution. By imposing homogeneity, not only are the relative loss responses exaggerated (all the percentage increases and decreases are larger for the restricted than for the unrestricted model), but perceived reduction of risk in the tail of the loss distribution tends to be overly optimistic. Failing to properly account for parameter heterogeneity could therefore result in too much implied risk capital.

Both the baseline and shock-conditional loss distributions seem to change noticeably with the addition of heterogeneous factor loadings. Allowing for regional heterogeneity appears to be more important than allowing for industry or sector heterogeneity. However, the biggest marginal change arises when allowing for full heterogeneity.

The apparently innocuous choice of identifying restriction - same default threshold versus same unconditional probability of default (or distance to default), by credit rating - makes a material difference. Under the same threshold (by rating) restriction, conditioning on risk factor forecasts changes firm default probabilities only somewhat: unconditional and conditional probabilities of default are highly correlated (96\%). By contrast, such conditioning has a significant impact under the same distance to default (by rating) restriction. The conditional default probabilities disperse resulting in a low correlation with unconditional default probabilities (79\%). 
Finally, we are able to assess the impact of granularity or portfolio size on the risk of the portfolio for a simplified version of the model where analytic solutions for unexpected loss (UL) are available. The lower the average correlation across firm returns, the greater is the potential for diversification. But to achieve the theoretical (asymptotic) lower bound to the UL, a relatively large $N$ is required when return correlations are low. A common rule of thumb for return diversification of a portfolio of equities is around 50. Default correlations are, of course, much lower than return correlations, and we show that to come within $3 \%$ of the asymptotic UL values, more than 5,000 firms are needed. Thus credit portfolios or credit derivatives such as CDOs which contains rather fewer number of firms most likely would still retain a significant degree of idiosyncratic risk. In the case, for instance, of our more modestly sized portfolio of 243 firms, the UL is some $44 \%$ above its asymptotic value.

The plan for the remainder of the paper is as follows: Section 2 provides a model of firm value and default. Section 3 covers some useful analytical results for the loss distribution of a credit portfolio. Section 4 presents the framework for conditional credit risk modeling including a brief overview of the global macroeconometric model. In Section 5 we introduce the credit portfolio and present the results from the multi-factor return regressions that link firm returns to the observable systematic risk factors from the macroeconomic engine. We present results for five models ranging from the homogeneous pooled model to one allowing for full heterogeneity, with intermediate specifications that allow for industry and geography effects. In Section 6 we consider how those models impact the resulting loss distributions under a variety of macroeconomic shock scenarios. In this section we also consider the impact of portfolio size and granularity on the resulting loss distribution. Some concluding remarks are provided in Section 7.

\section{$2 \quad$ Firm Value and Default ${ }^{1}$}

Most credit default models have two basic components: (i) a model of the firm value, and (ii) conditions under which default occurs. In this section we set out such a model by adapting the option theoretic default model due to Merton (1974) to our global macroeconometric specification of the systematic factors. Merton recognized that a lender is effectively writing a put option on the assets of the borrowing firm; owners and owner-managers (i.e. shareholders) hold the call option. If the value of the firm falls below a certain threshold, the owners will put the firm to the debtholders. Thus a firm is expected to default when the value of its assets falls below a threshold value determined by its liabilities.

The problem of modeling firm default inherits all the asymmetric information and agency problems between borrower and lender well known in the banking literature. The argument is roughly as follows. A firm, particularly if it is young and privately held, knows more about its health, quality

\footnotetext{
${ }^{1}$ This section follows the approach introduced in PSTW.
} 
and prospects than outsiders, e.g. lenders. Banks are particularly well suited to help overcome these informational asymmetries through relationship lending; learning by lending. Moreover, managers and owners of firms have an incentive to substitute higher risk for lower risk investments as they are able to receive upside gains (they hold a call option on the firm's assets) while lenders are not (they hold a put option). See the survey by James and Smith (2000) for a more extensive discussion, as well as Garbade (2001). If the firm is public, we have other sources of information such as quarterly and annual reports which, though accounting based, are then digested and interpreted by the market. Stock and bond prices serve as summary statistics of that information.

The scope for credit risk diversification thus can manifest itself through two channels: how firm value reacts to changes in the systematic risk factors and through differentiated default thresholds. Both channels need to be modeled. Since we shall be concerned with possibilities of diversification along the dimensions of geography and industry (or sector), we will consider firms $j, j=1, \ldots, N$, in country or region $i, i=1, \ldots, M$, and sector $s, s=1, \ldots, S$, and denote the firm's asset value at the end of period $t$ by $V_{j i s, t}$, and its outstanding stock of debt by $D_{j i s, t}$. According to Merton's model, default occurs at the maturity date of the debt, $t+H$, when the firm's assets, $V_{j i s, t+H}$, are less than the face value of the debt at that time, $D_{j i s, t+H}$. This is in contrast with the firstpassage model where default would occur the first time that $V_{j i s, t}$ falls below a default boundary (or threshold) over the period $t$ to $t+H .^{2}$ Under both models the default probabilities are computed with respect to the probability distribution of asset values at the terminal date, $t+H$ in the case of the original Merton model, and over the period from $t$ to $t+H$ in the case of the first-passage models. Although our approach can be adapted to the first-passage model, for simplicity we follow the Merton approach here.

We follow the approach developed in detail in PSTW where default is said to occur if the value of equity, $E_{j i s, t+H}$, falls below a possibly small but positive threshold value, $C_{j i s, t+H}$,

$$
E_{j i s, t+H}<C_{j i s, t+H}
$$

This is reasonable since technical default definitions used by banks and bondholders are typically weaker than outright bankruptcy. Moreover, because bankruptcies are costly and violations to the absolute priority rule in bankruptcy proceedings are so common, in practice the debtholders have an incentive to put the firm into receivership even before the equity value of the firm hits the zero value. The default point could vary over time and with firm's particular characteristics (region and sector being two of them, of course). It is, however, difficult to measure, since observable accounting-based factors are at best noisy and at worst reported with bias, highlighting the information asymmetry

\footnotetext{
${ }^{2}$ See Black and Cox (1976). More recent modeling approaches include direct strategic default considerations (e.g. Mella-Barral and Perraudin (1997)). Leland and Toft (1996) develop a model where default is determined endogenously, rather than by the imposition of a positive net worth condition. For a review of these models, see, for example, Lando (2004, Chapter 3).
} 
between managers (agents) and shareholders and debtholders (principals). ${ }^{3}$

To overcome these measurement difficulties and information asymmetries, we make use of a firm's credit rating $R \in \mathcal{R}=\{\mathcal{A} \mathcal{A} \mathcal{A}, \mathcal{A} \mathcal{A}, \ldots\} .{ }^{4}$ This will help us specifically in nailing down the default threshold, details of which are given below in Section 2.1. Naturally rating agencies have access to, and presumably make use of, private information about the firm to arrive at their firmspecific credit rating, in addition to incorporating public information such as, for instance, financial statements and equity returns.

To simplify the exposition here we adopt the standard practice and assume that asset values follow a Gaussian geometric random walk with a fixed drift.

$$
\ln \left(E_{j i s, t+1} / E_{j i s t}\right)=r_{j i s, t+1}=\mu_{j i s}+\sigma_{j i s} \varepsilon_{j i s, t+1},
$$

where $\varepsilon_{j i s, t+1} \backsim N(0,1)$, distributed independently across $t$ (but not necessarily across firms, $\sigma_{j i s}$ is the return innovation volatility and $\mu_{j i s}$ the drift of the one-period holding return, $r_{j i s, t+1}$. This specification is "unconditional" in the sense that it does not allow for the effects of business cycle and monetary policy variables on returns (and hence defaults). We shall return to conditional asset return specifications that allow for such effects in Section 2.2. The distribution of the $H$-period ahead holding period return associated with the above specification is then given by

$$
r_{j i s}(t, t+H)=\sum_{\tau=1}^{H} r_{j i s, t+\tau} \backsim N\left(H \mu_{j i s}, \sqrt{H} \sigma_{j i s}\right),
$$

where the notation $(t, t+H)$ is used throughout to mean over the period "from $t+1$ to $t+H$."

Default then occurs at the end of $H$ periods if the $H$-period change in firm value (or return) falls below the log threshold-equity ratio, or return default threshold, as in

$$
\ln \left(\frac{E_{j i s, t+H}}{E_{j i s, t}}\right)<\ln \left(\frac{C_{j i s, t+H}}{E_{j i s, t}}\right)
$$

or

$$
r_{j i s}(t, t+H)<\lambda_{j i s}(t, t+H) .
$$

Therefore, using (2), the firm's probability of default $(P D)$ at the terminal date $t+H$ is given by

$$
\pi_{j i s}(t, t+H)=\Phi\left(\frac{\lambda_{j i s}(t, t+H)-H \mu_{j i s}}{\sigma_{j i s} \sqrt{H}}\right),
$$

where $\Phi(\cdot)$ is the distribution function of the standard normal variate. The argument of $\Phi(\cdot)$ in (3) is sometimes called the distance to default $(D D)$. We may rewrite the $H$-period forward return default threshold as

$$
\lambda_{j i s}(t, t+H)=H \mu_{j i s}+\Phi^{-1}\left(\pi_{j i s}(t, t+H)\right) \sigma_{j i s} \sqrt{H} .
$$

\footnotetext{
${ }^{3}$ Duffie and Lando (2001), with this in mind, allow for imperfect information about the firm's assets and default threshold in the context of a first-passage model.

${ }^{4}$ For an overview of the rating industry, see Cantor and Packer (1995). For no reason other than convenience, we shall be using the ratings nomenclature used by Standard \& Poor's and Fitch.
} 
where $\Phi^{-1}\left(\pi_{j i s}(t, t+H)\right)$ is the quantile associated with the default probability $\pi_{j i s}(t, t+H)$. The firm defaults if its $H$-period return, $r_{j i s}(t, t+H)$, falls below its expected $H$-period return, less a multiple of its $H$-period volatility. ${ }^{5}$

\subsection{Identification of the Default Threshold}

In this section we provide a brief discussion of the problem of identifying the default threshold for each firm. Details can be found in Hanson, Pesaran and Schuermann (2005). In what follows we shall be suppressing the country and sector subscript for simplicity. Suppose now that at time $t$ we have a portfolio of size $N_{t}$ of firms, or credit exposures to those firms, and denote the exposure share or weight for the $j^{t h}$ firm as $w_{j t} \geq 0$ such that $\sum_{j=1}^{N_{t}} w_{j t}=1 .^{6}$ At time $t$ the expected portfolio default rate at the end of $H$-periods from now (e.g. one year) is then given by

$$
\pi(t, t+H)=\sum_{j=1}^{N_{t}} w_{j t} \Phi\left(\frac{\lambda_{j}(t, t+H)-H \mu_{j}}{\sigma_{j} \sqrt{H}}\right) .
$$

Relation (4) may be thought of as a moment estimator for the unknown thresholds $\lambda_{j}(t, t+H)$, since $\mu_{j}$ and $\sigma_{j}$ and $\pi(t, t+H)$ can be estimated from past observed returns and realized defaults. With one moment condition and $N_{t}$ unknown thresholds, one needs to impose $N_{t}-1$ identifying restrictions; for example, one could impose the same threshold for every firm in the portfolio. The number of required identifying restrictions could be reduced if further information can be used. One such type of information is provided by credit rating-specific default information.

Although firm-specific default probabilities, $\pi_{j}(t, t+H)$, are not observable, the default rate by rating, $\pi_{R}(t, t+H)$, can be estimated by pooling historical observations of firms' defaults in a particular rating class, using a sample spanning $t=1, \ldots, T$. In this case the number of identifying restrictions can be reduced to $N_{T}-k$, where $k$ denotes the number of rating categories, and $N_{T}$ the number firms in the portfolio at time $T$. There are two simple ways that identification can be achieved. One could, for example, impose the same distance to default on all firms in the same rating category, namely

$$
\frac{\hat{\lambda}_{j}(T, T+H)-H \bar{\mu}_{j}}{\bar{\sigma}_{j} \sqrt{H}}=D D_{R}(T, T+H) \quad \forall j \in R,
$$

where $\hat{\lambda}_{j}(T, T+H)$ is default threshold estimated on the basis of information available at time $T$, and $\bar{\mu}_{j}$ and $\bar{\sigma}_{j}$ are sample estimates of (unconditional) mean and standard deviations of one-period holding returns obtained over the period $t=1,2, \ldots, T$. Then with estimates of default frequencies by rating in hand, namely $\hat{\pi}_{R}(T, T+H)$, we are able to obtain an estimate of $D D_{R}(T, T+H)$

\footnotetext{
${ }^{5}$ Note that $\Phi^{-1}\left(\pi_{j i s}(t, t+H)\right)$ is negative for $\pi_{j i s}(t, t+H)<0.5$, which covers the default probability values typically considered in the literature.

${ }^{6}$ Note that we are disallowing short positions which is not very restrictive for credit assets.
} 
given $\mathrm{by}^{7}$

$$
\widehat{D D}_{R}(T, T+H)=\Phi^{-1}\left(\hat{\pi}_{R}(T, T+H)\right)
$$

and hence the firm-specific default thresholds

$$
\hat{\lambda}_{j}(T, T+H)=\bar{\sigma}_{j} \sqrt{H} \Phi^{-1}\left(\hat{\pi}_{R}(T, T+H)\right)+H \bar{\mu}_{j}
$$

Note that imposing the same $D D$ by rating as in (5) imposes the same unconditional $P D$ for each $R$-rated firm, as in (6), but allows for variation in the estimated default thresholds $\hat{\lambda}_{j}(T, T+H)$ across firms within a rating because of different unconditional means and standard deviations of returns, as in (7). Note also that each element on the right-hand-side of (7) is horizon dependent, making the default threshold horizon dependent.

Alternatively, one could impose the restriction that the default threshold $\hat{\lambda}_{j}(T, T+H)$ is the same across firms in the same rating category:

$$
\tilde{\lambda}_{j}(T, T+H)=\hat{\lambda}_{R}(T, T+H) \quad \forall j \in R
$$

which, when substituted into (4), now yields

$$
\hat{\pi}_{R}(T, T+H)=\sum_{j \in R} w_{j, T} \Phi\left(\frac{\hat{\lambda}_{R}(T, T+H)-H \bar{\mu}_{j}}{\bar{\sigma}_{j} \sqrt{H}}\right) .
$$

This is a non-linear equation that needs to be solved numerically for $\hat{\lambda}_{R}(T, T+H)$. Condition (9) implies that $D D$, and hence unconditional $P D$ s, will vary across firms within a rating, since $\hat{\lambda}_{R}(T, T+H)$ is chosen such that on average the $P D$ by firm with rating $R$ is equal to $\hat{\pi}_{R}(T, T+H)$.

\section{$2.2 \quad$ Firm-Specific Conditional Defaults}

For the credit risk analysis of different shock scenarios it is important to distinguish between conditional and unconditional default probabilities. For the conditional analysis we assume that conditional on the information available at time $t, \Omega_{t}$, and as before the return of firm $j$ in region $i$ and sector $s$ over the period $t$ to $t+H, r_{j i s}(t, t+H)=\ln \left(E_{j i s, t+H} / E_{j i s, t}\right)$, can be decomposed as

$$
r_{j i s}(t, t+H)=\mu_{j i s}(t, t+H)+\xi_{j i s}(t, t+H)
$$

where $\mu_{j i s}(t, t+H)$ is the (forecastable) conditional mean $\left(H\right.$-step ahead), and $\xi_{j i s}(t, t+H)$ is the (non-forecastable) component of the return process over the period $t$ to $t+H$. It may contain firm-specific idiosyncratic as well as systematic risk factor innovations. We shall assume that

$$
\xi_{j i s}(t, t+H) \sim N\left[0, \sigma_{j i s}^{2}(t, t+H)\right] .
$$

\footnotetext{
${ }^{7}$ Condition (5) implies that all firms with rating $R$ have the same unconditional distance to default and hence the same unconditional default probability, as in (6).
} 
We can now characterize the separation between a default and a non-default state with an indicator variable $z_{j i s}(t, t+H)$,

$$
z_{j i s}(t, t+H)=I\left[r_{j i s}(t, t+H)<\lambda_{j i s}(t, t+H)\right]
$$

such that,

$$
\begin{aligned}
& z_{j i s}(t, t+H)=1 \text { if } r_{j i s}(t, t+H)<\lambda_{j i s}(t, t+H) \Longrightarrow \text { Default }, \\
& z_{j i s}(t, t+H)=0 \text { if } r_{j i s}(t, t+H) \geq \lambda_{j i s}(t, t+H) \Longrightarrow \text { No Default. }
\end{aligned}
$$

Using the same approach as above, the $H$-period ahead conditional default probability for firm $j$ is given by

$$
\pi_{j i s}(t, t+H)=\Phi\left(\frac{\lambda_{j i s}(t, t+H)-\mu_{j i s}(t, t+H)}{\sigma_{j i s}(t, t+H)}\right) .
$$

$\mu_{j i s}(t, t+H)$ and $\sigma_{j i s}(t, t+H)$ can be estimated using the firm-specific multi-factor regressions using a sample ending in period $T$. In what follows we denote these estimates by $\hat{\mu}_{j i s}(T, T+H)$ and $\hat{\sigma}_{j i s}(T, T+H)$, respectively. The default thresholds, $\lambda_{j i s}(T, T+H)$, can be estimated, following the discussion in Section 2.1, by imposing either the same distance to default by rating, $D D_{R}(T, T+H)$, as in (5), or the same default threshold by rating, as in (8). Specifically, under the same $D D$ by rating, the firm-specific conditional $P D$ will be given by

$$
\hat{\pi}_{j i s}(T, T+H)=\Phi\left(\frac{\bar{\sigma}_{j i s} \sqrt{H} \Phi^{-1}\left[\hat{\pi}_{R}(T, T+H)\right]+H \bar{\mu}_{j i s}-\hat{\mu}_{j i s}(T, T+H)}{\hat{\sigma}_{j i s}(T, T+H)}\right) .
$$

Under the same default threshold by rating we have

$$
\hat{\pi}_{j i s}(T, T+H)=\Phi\left(\frac{\hat{\lambda}_{R}(T, T+H)-\hat{\mu}_{j i s}(T, T+H)}{\hat{\sigma}_{\xi j i s}(T, T+H)}\right),
$$

where $\hat{\lambda}_{R}(T, T+H)$ is determined by $(9)$.

Similarly, in the case of the same $D D$ by rating the empirical default condition for firm $j$ with credit rating $R$ can now be written as

$$
I\left[r_{j i s}(T, T+H)<\hat{\lambda}_{j i s}(T, T+H)\right]=1 \text { if } r_{j i s}(T, T+H)<\bar{\sigma}_{j i s} \sqrt{H} \Phi^{-1}\left[\hat{\pi}_{R}(T, T+H)\right]+H \bar{\mu}_{j i s},
$$

and in the case of the same default threshold by rating the default condition will be

$$
I\left[r_{j i s}(T, T+H)<\hat{\lambda}_{R}(T, T+H)\right]=1 \text { if } r_{j i s}(T, T+H)<\hat{\lambda}_{R}(T, T+H),
$$

where as before $\hat{\lambda}_{R}(T, T+H)$ is given as the solution to (9). Note that in the case of (18) there are only as many default thresholds as there are credit ratings, whereas in the case of (17), each default threshold is firm specific (through $\bar{\mu}_{j i s}$ and $\bar{\sigma}_{j i s}$ ). 
Mappings from credit ratings to default probabilities are typically obtained using corporate bond rating histories over many years, often 20 years or more, and thus represent averages across business cycles. The reason for such long samples is simple: default events for investment grade firms are quite rare; for example, the annual default probability even for an ' $\mathcal{A}$ ' rated firm is approximately one basis point for both Moody's and S\&P rated firms (see, for example, Jafry and Schuermann (2004)). Accordingly, we will make the further indentifying assumption that credit ratings are "cycle-neutral", in the sense that ratings are assigned only on the basis of firm-specific information and not on systematic or macroeconomic information. On this interpretation of credit ratings also see Saunders and Allen (2002) and Amato and Furfine (2004).

Given sufficient data for a particular region or country $i$ (the U.S. comes to mind) or sector $s$, one could in principle consider default probabilities that vary over those dimensions as well. However, since a particular firm $j$ 's default is only observable once, multiple (serial) bankruptcies notwithstanding, it makes less sense to allow $\pi$ to vary across $j .^{8}$ Empirically, then, we abstract from possible variation in default rates across regions and sectors, so that probabilities of default vary only across credit ratings and over time.

Finally, another important source of heterogeneity that could be of particular concern for our multi-country analysis is the differences that prevail in bankruptcy laws and regulations across countries. However, by using rating agency default data, which broadly speaking are based on homogeneous definition of default, we expect our analysis to be reasonably robust to such heterogeneities.

\section{Credit Loss Distribution ${ }^{9}$}

The complicated relationship between return correlations and defaults manifest itself at the portfolio level. Consider a credit portfolio composed of $N$ different credit assets such as loans at date $t$, and for simplicity assume that loss given default $(L G D)$ is $100 \%$, meaning that no recovery is made in the event of default. Then we may define loss as a fraction of total exposure by

$$
\ell_{N, t+1}=\sum_{j=1}^{N} w_{j} z_{j, t+1}
$$

\footnotetext{
${ }^{8}$ To be sure, one is not strictly prevented from obtaining firm-specific default probabilities estimates at a given point in time. The bankruptcy models of Altman (1968), Lennox (1999) and Shumway (2001) are such examples, as is the industry model by KMV (Kealhofer and Kurbat (2002)). However, all of these studies focus on just one country at a time (the U.S. and U.K in this list) and do not address the formidable challenges of point in time bankruptcy forecasting with a multi-country portfolio.

${ }^{9}$ This section presents a synopsis of results developed in detail in Hanson, Pesaran and Schuermann (2005).
} 
where $w_{j}$ is the exposure share, where $w_{j} \geq 0$ and $\sum_{j=1}^{N} w_{j}=1$, and $z_{j, t+1}=I\left(r_{j, t+1}<\lambda_{j t}\right)$, with $\lambda_{j t}$ assumed as given. ${ }^{10}$ Under the Vasicek model

$$
\operatorname{Var}\left(\ell_{N, t+1}\right)=\pi(1-\pi)\left(\sum_{j=1}^{N} w_{j}^{2}\right)+\pi(1-\pi) \rho^{*}\left(\sum_{j \neq j^{\prime}}^{N} w_{j} w_{j^{\prime}}\right)
$$

where $\pi=E\left(z_{j, t+1}\right)$, which is the same for all firms, and $\rho^{*}$ is the default correlation,

$$
\rho^{*}(\pi, \rho)=\frac{E\left\{\left[\Phi\left(\frac{\Phi^{-1}(\pi)}{\sqrt{1-\rho}}-\sqrt{\frac{\rho}{1-\rho}} f_{t+1}\right)\right]^{2}\right\}-\pi^{2}}{\pi(1-\pi)},
$$

where expectations are taken with respect to the distribution of $f_{t+1}$, assumed here to be $N(0,1) .{ }^{11}$ For example, for $\pi=0.01$, and $\rho=0.30$, we have $\rho^{*}=0.05$. Since, $\sum_{j=1}^{N} w_{j}=1$, it is easily seen that

$$
\sum_{j=1}^{N} w_{j}^{2}+\sum_{j \neq j^{\prime}}^{N} w_{j} w_{j^{\prime}}=1
$$

and hence

$$
\operatorname{Var}\left(\ell_{N, t+1}\right)=\pi(1-\pi)\left\{\rho^{*}+\left(1-\rho^{*}\right) \sum_{j=1}^{N} w_{j}^{2}\right\}
$$

Under

$$
\sum_{j=1}^{N} w_{j}^{2} \rightarrow 0, \text { as } N \rightarrow \infty
$$

which is often referred to as the granularity condition, the second term in brackets in (21) become negligible as $N$ becomes very large, and $\operatorname{Var}\left(\ell_{N, t+1}\right)$ converges to the first term which will be non-zero for $\rho^{*} \neq 0$. Hence, in the limit the unexpected loss is bounded by $\sqrt{\pi(1-\pi) \rho^{*}}$. For a finite value of $N$, the unexpected loss is minimized by adopting an equal weighted portfolio, with $w_{j}=1 / N$. Full diversification is possible only in the extreme case where $\rho^{*}=0$ (which is implied by $\rho=0$ ), and assuming that the above granularity condition is satisfied.

The loss distribution associated with this homogeneous model is derived in Vasicek (1991, 2002) and Gordy (2000). Not surprisingly, Vasicek's limiting (as $N \rightarrow \infty$ ) distribution is also fully determined in terms of $\pi$ and $\rho$. The former parameter sets the expected loss of the portfolio, while the latter controls the shape of the loss distribution. In effect one parameter, $\rho$, controls all aspects of the loss distribution: its volatility, skewness and kurtosis. It would not be possible to calibrate two Vasicek loss distributions with the same expected and unexpected losses, but with different degrees of fat-tailedness, for example. ${ }^{12}$

\footnotetext{
${ }^{10}$ To simplify the notations and without loss of generality, in this section we assume $N$ and the exposure weights are time invariant.

${ }^{11}$ For a derivation of (20), see Hanson, Pesaran and Schuermann (2005).

${ }^{12}$ The literature on modeling correlated defaults has been growing enormously. For a recent survey, see Lando (2004, ch. 9).
} 
Further, Vasicek's distribution does not depend on the portfolio weights so long as (22) is satisfied. Therefore, for sufficiently large portfolios that satisfy the granularity condition, (22), there is no further scope for credit risk diversification if attention is confined to the homogeneous return model that underlies Vasicek's loss distribution. Also, Vasicek's set up does not allow conditional risk modeling where the effects of macroeconomic shocks on credit loss distribution might be of interest. With these considerations in mind, we allow for systematic factors and heterogeneity along several dimensions. These are: 1) multiple and observable factors, 2) firm fixed effects, 3) differentiated default thresholds, and 4) differentiated factor sensitivities (analogous to firm "betas") by region, sector or even firm-specific. If the Vasicek model lies at the fully homogeneous end of the spectrum, the model laid out in Section 2 above describes the fully heterogeneous end. How much does accounting for heterogeneity matter for credit risk? The outcomes we are interested in exploring are different measures of credit risk, be it means or volatilities of credit losses (expected and unexpected losses in the argot of risk management), as well as quantiles in the tails or valueat-risk (VaR). Before we are able to answer some of these questions we first need to introduce the macroeconomic or systematic risk model that we plan to utilize in our empirical analysis.

\section{Conditional Credit Risk Modeling}

\subsection{The Macroeconomic Engine: GVAR}

The conditional loss distribution of a given credit portfolio can be derived by linking up the return processes of individual firms, initially presented in equation (10), explicitly to the macro and global variables in the GVAR model. The macroeconomic engine driving the credit risk model is described in detail in PSW. We only provide a very brief, non-technical overview here. The GVAR is a global quarterly model estimated over the period 1979Q1-1999Q1 comprising a total of 25 countries which are grouped into 11 regions, (shown in bold in Table 1 from PSTW, reproduced here for convenience). The advantage of the GVAR is that it allows for a true multi-country setting; however, it can become computationally demanding very quickly. For that reason we model the seven key economies of the U.S., Japan, China, Germany, U.K., France and Italy as regions of their own while grouping the other 18 countries into four regions. ${ }^{13}$ The output from these countries comprises around $80 \%$ of world GDP (in 1999).

\section{[Insert Table 1 about here]}

In contrast to existing modeling approaches, in the GVAR the use of cointegration is not confined to a single country or region. By estimating a cointegrating model for each country/region separately, the model also allows for endowment and institutional heterogeneities that exist across the

\footnotetext{
${ }^{13}$ See PSW, Section 8, for details on cross-country aggregation into regions.
} 
different countries. Accordingly, specific vector error-correcting models (VECM) are estimated for individual countries (or regions) by relating domestic macroeconomic variables such as GDP, inflation, equity prices, money supply, exchange rates and interest rates to corresponding, and therefore country-specific, foreign variables constructed exclusively to match the international trade pattern of the country/region under consideration. By making use of specific exogeneity assumptions regarding the 'rest of the world' with respect to a given domestic or regional economy, the GVAR makes efficient use of limited amounts of data and presents a consistently-estimated global model for use in portfolio applications and beyond. ${ }^{14}$

The GVAR allows for interactions to take place between factors and economies through three distinct but interrelated channels:

- Contemporaneous dependence of domestic on foreign variables and their lagged values;

- Dependence of country specific variables on observed common global effects such as oil prices;

- Weak cross-sectional dependence of the idiosyncratic shocks.

The individual models are estimated allowing for unit roots and cointegration assuming that region-specific foreign variables are weakly exogenous, with the exception of the model for the U.S. economy which is treated as a closed economy model. The U.S. model is linked to the outside world through exchange rates, which in turn are themselves determined by the rest of the region-specific models. PSW show that the careful construction of the global variables as weighted averages of the other regional variables leads to a simultaneous system of regional equations that may be solved to form a global system. They also provide theoretical arguments as well as empirical evidence in support of the weak exogeneity assumption that allows the region-specific models to be estimated consistently.

The conditional loss distribution of a given credit portfolio can now be derived by linking up the return processes of individual firms, initially presented in equation (10), explicitly to the macro and global variables in the GVAR model. We provide a synopsis of the model developed in full detail in PSTW.

\subsection{Firm Returns Based on Observed Common Factors Linked to GVAR}

Here we extend the firm return model by incorporating the full dynamic structure of the systematic risk factors captured by the GVAR. We present a notationally simplified version of the model outlined in detail in PSTW. Accordingly, a firm's return is assumed to be a function of changes in

\footnotetext{
${ }^{14}$ For a more updated version of the GVAR model which covers a longer period and a larger number of countries see Dees, di Mauro, Pesaran and Smith (2005). This version also provides a theoretical framework where the GVAR is derived as an approximation to a global unobserved common factor model.
} 
the underlying macroeconomic factors (domestic and foreign), the exogenous global variables (in our application oil prices) and the firm-specific idiosyncratic shocks $\eta_{j i s, t+\tau}$ :

$$
r_{j i s, t+\tau}=\alpha_{j i s}+\gamma_{j i s}^{\prime} \mathbf{f}_{t+\tau}+\sigma_{j i s} \eta_{j i s, t+\tau}, t=1,2, \ldots, T
$$

where $\eta_{j i s, t+\tau} \backsim i . i . d . N(0,1), \tau=1,2, \ldots, H, r_{j i s, t+\tau}$ is the equity return of firm $j\left(j=1, \ldots, n c_{i}\right)$ in region $i$ and sector $s, \alpha_{j i s}$ is a regression constant (or firm "alpha"), $\gamma_{j i s}$ are the factor loadings (firm "betas"), and $\mathbf{f}_{t+\tau}$ collects all the observed macroeconomic variables plus oil prices in the global model (totaling 64 in PSW). To be sure, these return regressions are not prediction equations per se as they depend on contemporaneous variables.

The GVAR model provides forecasts of all the global variables that directly or indirectly affect the returns. As a result default correlation enters through the shared set of common factors, $\mathbf{f}_{t+\tau}$, and the factor loadings, $\gamma_{j i s}$. If the model captures all systematic risk, the idiosyncratic risk components of any two companies in the model would be uncorrelated, namely the idiosyncratic risks ought to be cross-sectionally uncorrelated. In practice, of course, it will be hard to absorb all of the cross-section correlation with the systematic risk factors modeled by the GVAR.

Note that we started by decomposing firm returns into forecastable and non-forcastable components in (10), namely $r_{j i s}(t, t+H)=\mu_{j i s}(t, t+H)+\xi_{j i s}(t, t+H)$. In the case of the above specification we have

$$
r_{j i s}(t, t+H)=H \alpha_{j i s}+\gamma_{j i s}^{\prime} \sum_{\tau=1}^{H} \mathbf{f}_{t+\tau}+\sigma_{j i s} \sum_{\tau=1}^{H} \eta_{j i s, t+\tau},
$$

and as an illustration assuming a first-order vector autoregression for the common factors:

$$
\mathbf{f}_{t+\tau}=\Lambda \mathbf{f}_{t+\tau-1}+\mathbf{v}_{t+\tau}
$$

we have ${ }^{15}$

$$
\mu_{j i s}(t, t+H)=H \alpha_{j i s}+\gamma_{j i s}^{\prime}\left(\sum_{\tau=1}^{H} \boldsymbol{\Lambda}^{\tau}\right) \mathbf{f}_{t},
$$

and

$$
\xi_{j i s}(t, t+H)=\gamma_{j i s}^{\prime}\left(\sum_{\tau=1}^{H} \boldsymbol{\Psi}_{H-\tau} \mathbf{v}_{t+\tau}\right)+\sigma_{j i s} \sum_{\tau=1}^{H} \eta_{j i s, t+\tau}
$$

where

$$
\boldsymbol{\Psi}_{H-\tau}=\mathbf{I}+\boldsymbol{\Lambda}+\ldots+\boldsymbol{\Lambda}^{H-\tau} .
$$

The composite innovation $\xi_{j i s}(t, t+H)$ contains the idiosyncratic innovation $\eta_{j i s, t+\tau}$, and common macro innovations from the GVAR, here represented by $\mathbf{v}_{t+\tau}$, for $\tau=1,2, \ldots, H$. The predictable component is likely to be weak and will depend on the size of the factor loadings, $\gamma_{j i s}$, and the extent to which the underlying global variables are cointegrating. In the absence of any cointegrating

\footnotetext{
${ }^{15}$ Note that for a pure random walk, $\boldsymbol{\Lambda}=\mathbf{0}$, and conditional and unconditional returns processes are identical.
} 
relations in the global model, none of the asset returns are predictable. As it happens the econometric evidence presented in PSW strongly supports the existence of 36 cointegrating relations in the 63-equation global model and is, therefore, compatible with some degree of predictability in asset returns, at least at the quarterly horizon modeled here. The extent to which asset returns are predicted could reflect time-varying risk premia and does not necessarily imply market inefficiencies. Our modelling approach provides an operational procedure for relating excess returns of individual firms to all the observable macro factors in the global economy.

\subsection{Expected Loss Due to Default}

Given the value change process for firm $j$, defined by $(23)$, with $\mu_{j i s}(T, T+H)$ and $\xi_{j i s}(T, T+H)$ by $(25)$ and (26), and the return default threshold, $\hat{\lambda}_{R}(T, T+H)$, obtainable from an initial credit rating (see Section 2), we are now in a position to compute (conditional) expected loss. Suppose we have data for firms and systematic factors in the GVAR for a sample period $t=1, \ldots, T$. We need to define the expected loss to firm $j$ at time $T+H$ given information available to the lender (e.g. a bank) at time $T$, which we assume is given by $\Omega_{T}$. Default occurs when the firm's return falls below the return default threshold $\hat{\lambda}_{j i s}(T, T+H)$ or $\tilde{\lambda}_{j i s}(T, T+H)$ defined by (7) and (8), depending on the scheme used to identify the thresholds. Expected loss at time $T$ (and realized at $T+H), E_{T}\left(L_{j i s, T+H}\right)=E\left(L_{j i s, T+H} \mid \Omega_{T}\right)$, is given by (using $\tilde{\lambda}_{j i s}(T, T+H)=\hat{\lambda}_{R}(T, T+H)$, for $j \in R$, for example) and

$E_{T}\left(L_{j i s, T+H}\right)=\operatorname{Pr}\left[\xi_{j i s}(T, T+H)<\tilde{\lambda}_{j i s}(T, T+H)-\mu_{j i s}(T, T+H) \mid \Omega_{T}\right] \times A_{j i s, T} \times E_{T}\left(\varphi_{j i s, T+H}\right)$,

where $A_{j i s, T}$ is the exposure assuming no recoveries (typically the face value of the loan) and is known at time $T$, and $\varphi_{j i s, T+H}$ is the percentage of exposure which cannot be recovered in the event of default or loss given default $(L G D)$. Typically $\varphi_{j i s, T+H}$ is not known at time of default and is therefore treated as a random variable over the unit interval. In what follows we make the simplifying assumption that $L G D$ is $100 \%$.

Substituting (23) into (27) we obtain:

$$
E_{T}\left(L_{j i s, T+H}\right)=\pi_{j i s}(T, T+H) \times A_{j i s, T},
$$

where

$$
\pi_{j i s}(T, T+H)=\operatorname{Pr}\left[\xi_{j i s}(T, T+H)<\tilde{\lambda}_{j i s}(T, T+H)-\mu_{j i s}(T, T+H) \mid \Omega_{T}\right] .
$$

is the conditional default probability over the period $T$ to $T+H$, formed at time $T$. Under the assumption that the macro and the idiosyncratic shocks are normally distributed and that the parameter estimates are given, we have the following expression for the probability of default over 
$T$ to $T+H$ formed at $T^{16}$

$$
\pi_{j i s}(T, T+H)=\Phi\left(\frac{\tilde{\lambda}_{j i s}(T, T+H)-\mu_{j i s}(T, T+H)}{\sigma_{\xi j i s}(T, T+H)}\right),
$$

where $\sigma_{\xi j i s}(T, T+H)=\sqrt{\operatorname{Var}\left[\xi_{j i s}(T, T+H) \mid \Omega_{T}\right]}$. Exact expressions for $\mu_{j i s}(t, t+H)$ and $\sigma_{\xi j i s}(t, t+H)$ will depend on the nature of the global model used to identify the macro innovations. In the case of the illustrative example given above, we have

$$
\operatorname{Var}\left[\xi_{j i s}(T, T+H) \mid \Omega_{T}\right]=\gamma_{j i s}^{\prime}\left(\sum_{\tau=1}^{H} \Psi_{H-\tau} \boldsymbol{\Omega}_{v} \Psi_{H-\tau}^{\prime}\right) \gamma_{j i s}+H \sigma_{j i s}^{2},
$$

where $\boldsymbol{\Omega}_{v}$ is the covariance matrix of the common shocks, $\mathbf{v}_{t}$. The relevant expressions for $\mu_{j i s}(T, T+$ $H)$ and $\sigma_{\xi j i s}(T, T+H)$ in the case of the GVAR model are provided in the Supplement to PSTW.

The expected loss due to default of a loan (credit) portfolio can now be computed by aggregating the expected losses across the different loans. Denoting the loss of a loan portfolio over the period $T$ to $T+H$ by $L_{T+H}$ we have

$$
E_{T}\left(L_{T+H}\right)=\sum_{i=0}^{N} \sum_{j=1}^{n c_{i}} \pi_{j i s}(T, T+H) \times A_{j i s, T}
$$

where $n c_{i}$ is the number of obligors (which could be zero) in the bank's loan portfolio resident in country/region $i$.

Finally note that, $\mu_{j i s, T}$ is the explained or expected component of firm $j$ 's return, obtained from the multi-period GVAR forecasts which in general could depend on macroeconomic shocks worldwide. Thus, although individual firms operate in a particular country/region $i$, their probability of default can be affected by global macro economic conditions.

\subsection{Simulation of the Loss Distribution}

The expected loss as well as the entire loss distribution can be computed once the GVAR model parameters, the return process parameters in (23) and the thresholds using either (7) or (8), have been estimated for a sample of observations $t=1,2, \ldots, T$. We do this by stochastic simulation using draws from the joint distribution of the shocks, $\xi_{j i s}(T, T+H)$, which is assumed to have a conditional normal distribution with variance $\sigma_{\xi j i s}^{2}(T, T+H)$.

Denote the $b^{\text {th }}$ draw of this vector by $\xi_{j i s}^{(b)}(T, T+H)$, and compute the $H$-period firm-specific return, $r_{i j s}^{(b)}(T, T+H)$, noting that

$$
r_{i j s}^{(b)}(T, T+H)=\mu_{j i s}(T, T+H)+\xi_{j i s}^{(b)}(T, T+H),
$$

\footnotetext{
${ }^{16}$ Joint normality is sufficient but not necessary for $\xi_{j i s}(T, T+H)$ to be approximately normally distributed. This is because $\xi_{j i s}(T, T+H)$ is a linear function of a large number of weakly correlated shocks (63 in our particular application).
} 
where $\mu_{j i s}(T, T+H)$ is derived from the GVAR forecasts (along the lines of (25)), and

$$
\xi_{j i s}^{(b)}(T, T+H)=\psi_{j i s, H} Z_{0}^{(b)}+\sigma_{j i s} \sqrt{H} Z_{j i s}^{(b)}
$$

is the composite innovation, where $Z_{0}^{(b)}$ and $Z_{j i s}^{(b)}$ are independent draws from $N(0,1)$. The loading coefficients $\psi_{j i s, H}$ and $\sigma_{j i s} \sqrt{H}$ are determined by the parameters of the GVAR and the coefficients of the asset return regressions, (23). In the case of the GVAR model the relevant expressions for the simulation of the multi-period returns are provided in Section B of the Supplement to PSTW.

Note that $Z_{0}^{(b)}$ is shared by all firms for a given draw $b$. Details on the derivation of $\psi_{j i s, H}$ for the GVAR model can be found in PSTW. The idiosyncratic portion of the innovation is comprised of the firm specific volatility, $\sigma_{j i s}$, estimated using a sample ending in periods $T$, and a firm specific standard normal draw, $Z_{j i s}^{(b)}$. One may then simulate the loss at the end of period $T+H$ using (known) loan face values, $A_{j i s, T}$, as exposures:

$$
L_{T+H}^{(b)}=\sum_{i=0}^{N} \sum_{j=1}^{n c_{i}} I\left[r_{i j s}^{(b)}(T, T+H)<\tilde{\lambda}_{j i s}(T, T+H)\right] A_{j i s, T} .
$$

The simulated expected loss due to default is given by (using $B$ replications)

$$
\bar{L}_{B, T+H}=\frac{1}{B} \sum_{b=1}^{B} L_{T+H}^{(b)} \quad \stackrel{p}{\rightarrow} E_{T}\left(L_{T+H}\right), \text { as } B \rightarrow \infty .
$$

The simulated loss distribution is given by ordered values of $L_{T+H}^{(b)}$, for $b=1,2, \ldots, B$. For a desired percentile, for example the $99 \%$, and a given number of replications, say $B=100,000$, credit value at risk is given as the $1000^{\text {th }}$ highest loss.

\section{An Empirical Application}

\subsection{The Credit Portfolio}

To analyze the effects of different model specifications, parameter homogeneity versus heterogeneity, we construct a fictitious large-corporate loan portfolio. This portfolio is an extended version of that used in PSTW and is summarized in Table 2a. It contains a total of 243 companies, resident in 21 countries across 10 of the 11 regions in the GVAR model. In order for a firm to enter our sample, several criteria had to be met. We restricted ourselves to major, publicly traded firms with a credit rating from either Moody's or S\&P. Thus, for example, Chinese companies were not included for lack of a credit rating. The firms should be represented within the major equity index for that country. We favored firms for which equity return data was available for the entire sample period, i.e. going back to 1979. Typically this would exclude large firms such as telephone operators which in many instances have been privatized only recently, even though they may represent a significant 
share in their country's dominant equity index today. The data source is Datastream, and we took their Total Return Index variable which is a cum dividend return measure.

The third column in Table 2a indicates the inception of the equity series available for the multifactor regressions. We allocated exposure roughly by share of output of the region (in our "world" of 25 countries). Within a region, loan exposure is randomly assigned. Loss given default is assumed to be $100 \%$ for simplicity. Table $2 \mathrm{~b}$ provides summary information of the number of firms in the portfolio by industry.

[Insert Tables $2 \mathrm{a} \& 2 \mathrm{~b}$ about here]

In order to obtain estimates for the rating-specific default frequencies $\left(\hat{\pi}_{R, T+H \mid T}\right)$, we make use of the rating histories from Standard \& Poor's spanning 1981-1999, roughly the same sample period as is covered by our GVAR model. The results are presented in Table 3 below for the range of ratings that are represented in our portfolio of firms, namely $\mathcal{A} \mathcal{A} \mathcal{A}$ to $\mathcal{B}$. Empirical default probabilities,

$\hat{\pi}_{R, T+\tau}$, for $\tau=1,2, \ldots, H$ are obtained using default intensity-based estimates detailed in Lando and Skødeberg (2002) and computed for different horizons under the assumption that the credit migrations are governed by a Markov process (in our application $H=4$ quarters). This assumption is reasonable for moderate horizons, up to about two years; see Bangia et al. (2002). Since S\&P rates only a subset of firms (in $1981 \mathrm{~S} \& \mathrm{P}$ rated 1,378 firms of which about $98 \%$ were U.S. domiciled; by early 1999 this had risen to 4,910, about 68\% U.S.), it is reasonable to assign a non-zero (albeit very small) probability of default, even if the empirical estimate is zero. This is particularly relevant if we wish to infer default behavior for a much broader set of firms than is covered by the rating agencies. With this in mind, we impose a lower bound on the quarterly default frequency of 0.025 basis points per quarter or 0.1 basis points per annum. As can be seen in Table 3, this constraint is binding only for the $\mathcal{A} \mathcal{A} \mathcal{A}$ rating. In this table we also show in parentheses the exposure share by rating and the resulting EL. Based on the exposures in our portfolio, the (unconditional) expected default (or loss under the maintained assumption of no recovery) over one year is $0.294 \%$ or $29.4 \mathrm{bp}$ (basis points), bolded in the table.

\section{[Insert Table 3 about here]}

\subsection{Multi-factor Return Regressions: Specification, Estimation and Selection}

With the GVAR framework serving as the global economic engine, multi-factor return regressions are specified in terms of the observed macro factors in the GVAR model. A general form of these return regressions is given by (23). Given the diverse nature of the firms in our portfolio, one is tempted to include all the domestic, foreign and global factors (i.e. oil price changes) in the multi-factor regressions. Such a general specification may be particularly important in the case where a multinational is resident in one country, but the bulk of its operations takes place in the 
global arena. However, because there is likely to be a high degree of correlation between some of the domestic and foreign variables (in particular the domestic and foreign real equity prices), it is by no means obvious that a general-to-specific model selection process would be appropriate, particularly considering the short time series data available relative to the number of different factors in the GVAR.

An alternative model selection strategy, which we adopted in PSTW and follow in this paper, is to view the 243 multi-factor regressions as forming a panel data model with heterogeneous coefficients. Such panels have been studied by Pesaran and Smith (1995) and Pesaran, Smith and Im (1996) where it is shown that instead of considering firm-specific estimates one could base the analysis on the means of the estimated coefficients, referred to as the mean group estimates (MGE). This approach assumes that the variations of factor loadings across firms in different regions are approximately randomly distributed around fixed means. This is the standard random coefficient model introduced into the panel literature by Swamy (1970) and used extensively in the empirical literature. ${ }^{17}$ The choice of the factors in the multi-factor regressions can now be based on the statistical significance of the (population) mean coefficients by using the MGE to select a slimmeddown regressor set. ${ }^{18}$

The above factor selection procedure applied to the panel of 243 firms led to the following set of factors: changes in domestic or foreign real equity prices, which we denote by $\Delta \tilde{q}_{i, t+1}$, domestic interest rate $\left(\Delta \rho_{i, t+1}\right)$ and oil price changes $\left(\Delta p_{t+1}^{o}\right)$. We ran two sets of multi-factor regressions (including the interest rate and oil price variables); one with $\Delta q_{i, t+1}$ (the domestic aggregate equity return variable) and another with $\Delta q_{i t}^{*}$ (the foreign country-specific equity return variable), and selected the regression with the higher $\bar{R}^{2}$. For three-quarters of the portfolio (183 firms) the domestic equity market return was chosen. This fully heterogeneous return equation (to be denoted as model $\mathrm{M}_{0}$ ) is given by

$$
r_{j i s, t+1}=\alpha_{j i s}+\beta_{1, j i s} \Delta \tilde{q}_{i, t+1}+\beta_{2, j i s} \Delta \rho_{i, t+1}+\beta_{3, j i s} \Delta p_{t+1}^{o}+\varepsilon_{j i s, t+1},
$$

where the idiosyncratic errors, $\varepsilon_{j i s, t+1}$, are assumed to be i.i.d.N $\left(0, \sigma_{j i s}^{2}\right)$. As credit rating information is used, default thresholds are computed using (7) and (8), depending on whether we fix $D D$ or $\lambda$ by rating.

The summary of the final set of multi-factor regressions of (35) and the associated MG estimates are given in Table 4 . In this specification changes in equity prices, interest rates and oil prices remain the key driving factors in the multi-factor regressions.

\section{[Insert Table 4 about here]}

As is to be expected, the portfolio equity "beta" is highly significant, but somewhat below unity at 0.918. An increase in the rate of interest results in a decline in firm returns while the overall effect

\footnotetext{
${ }^{17} \mathrm{~A}$ recent review of the random coefficient models is provided by Hsiao and Pesaran (2004).

${ }^{18}$ The appropriate test statistics for this purpose are given in PSTW, Section 6.
} 
of the oil price changes is positive. This seems a reasonable outcome for energy and petrochemical companies and for some of the banks, although one would not expect this result to be universal. In fact we do observe considerable variations in the individual estimates of the coefficients of oil prices changes across different firms in our portfolio. In the final regressions, of the 243 firm regressions, the coefficient on oil price changes was positive for 144 firms (about $59 \%$ of the total), and negative for the remaining firms. The MGE for each subset was also significant. A pooled estimate would, of course, impose the same factor loadings, in this case positive, on all firms. ${ }^{19}$

The lack of other observable systematic risk factors entering the return model confirms that most information relevant for firm returns is contained in the contemporaneous market return. Only interest rates and oil prices changes provided marginal explanatory power. To be sure, when forecasting the macroeconomic variables, and when conducting scenario analyses, the dynamics of all the variables modeled in the GVAR (all 63 of them, plus oil prices) can still affect returns through their possible impacts on equity returns and interest rates. A direct presence in the firm return equation is not necessary for real output, for example, to influence returns. Output shocks influence returns and credit losses to the extent that real output, interest rates and stock market returns are contemporaneously correlated.

In addition to the above fully heterogeneous specification, we also consider a number of specifications with differing degrees of slope and error variance heterogeneity, but based on the same three systematic factors $\left(\Delta \tilde{q}_{i, t+1}, \Delta \rho_{i, t+1}, \Delta p_{t+1}^{o}\right)$. We consider the following additional models:

$\mathbf{M}_{1}$ (Fully Homogeneous Model): Pooled return equations with the same "alpha" and "beta" across all 243 firms in the portfolio:

$$
r_{j i s, t+1}=\alpha+\beta_{1} \Delta \tilde{q}_{i, t+1}+\beta_{2} \Delta \rho_{i, t+1}+\beta_{3} \Delta p_{t+1}^{o}+\varepsilon_{j i s, t+1},
$$

where the error variances are assumed to be the same for all firms, i.e. $\sigma_{j i s}^{2}=\sigma_{\varepsilon}^{2} \forall j i s .^{20}$

$\mathbf{M}_{2}$ (Firm Fixed Effects): This is the standard fixed effects specification:

$$
r_{j i s, t+1}=\alpha_{j i s}+\beta_{1} \Delta \tilde{q}_{i, t+1}+\beta_{2} \Delta \rho_{i, t+1}+\beta_{3} \Delta p_{t+1}^{o}+\varepsilon_{j i s, t+1}
$$

where the error variances are assumed to be the same for all firms, as in the model $\mathrm{M}_{1}$.

$\mathbf{M}_{3}$ : (Industry/Sector Fixed and Marginal Effects): This model imposes the same intercept ("alphas") and slopes ("betas") within an industry/sector but allows those parameters to vary across industries:

$$
\begin{aligned}
r_{j i s, t+1}= & \sum_{s=1}^{S} \alpha_{s} S D_{s}+\sum_{s=1}^{S} \beta_{1 s} S D_{s} \Delta \tilde{q}_{i, t+1}+\sum_{s=1}^{S} \beta_{2 s} S D_{s} \Delta \rho_{i, t+1} \\
& +\sum_{s=1}^{S} \beta_{3 s} S D_{s} \Delta p_{t+1}^{o}+\varepsilon_{j i s, t+1},
\end{aligned}
$$

\footnotetext{
${ }^{19}$ Similarly for $\Delta \rho_{i, t+1}, 38 \%$ of firms actually have a positive coefficient.

${ }^{20}$ The parameters $\alpha$ and $\beta_{i}^{\prime}$ are estimated by pooled OLS.
} 
where $S D_{s}$ is a sector dummy variable which takes the value of 1 for sector $s$ and 0 otherwise, for all $t, i$ and $j$. All firms within a given sector have the same error variance, but those variances are allowed to vary across industries.

$\mathbf{M}_{4}$ : (Region Fixed and Marginal Effects): In this model we impose the same intercept ("alpha") and slope ("beta") within a region but allow those parameters to vary across regions.

$$
\begin{aligned}
r_{j i s, t+1}= & \sum_{i=1}^{M} \alpha_{i} R D_{i}+\sum_{i=1}^{M} \beta_{1 i} R D_{i} \Delta \tilde{q}_{i, t+1}+\sum_{i=1}^{M} \beta_{2 i} R D_{i} \Delta \rho_{i, t+1} \\
& +\sum_{i=1}^{M} \beta_{3 i} R D_{i} \Delta p_{t+1}^{o}+\xi_{j i s, t+1},
\end{aligned}
$$

where $R D_{i}$ is dummy variable which takes the value of 1 for region $i$ and 0 otherwise, for all $t, s$ and $j$. All firms within a given region have the same error variance, but those variances are allowed to vary across regions.

Model $\mathrm{M}_{2}$ is arguably the simplest complication beyond a fully homogeneous model in that it allows firm fixed effects (firm "alphas") but still imposes the same error variance on all firms. Models $\mathrm{M}_{3}$ and $\mathrm{M}_{4}$ explore the impact of parameter (mean and variance) heterogeneity by industry and region respectively.

Table 5 summarizes the regression results for the remaining models, $\mathrm{M}_{1}$ to $\mathrm{M}_{4}$. The equity factor loading is highly statistically significant (1\% or better) across all models, and for the pooled models, with or without a firm fixed effect, $\mathrm{M}_{2}(0.869)$ and $\mathrm{M}_{1}(0.865)$ respectively, the coefficient is close to the MG estimate for the heterogeneous model, $\mathrm{M}_{0}$ (0.918). There is, however, considerable variation across industries $\left(\mathrm{M}_{3}\right)$ and regions $\left(\mathrm{M}_{4}\right)$. For the industry model, the equity "beta" is lowest for Communication, Electric \& Gas and Non-durable Manufacturing, both 0.752, and highest for FIRE (Finance, Insurance and Real Estate), 0.909. The sector equity "beta" closest to the pooled model is Agriculture, Mining \& Construction, 0.889 .

[Insert Table 5 about here]

There is even more variation in the equity "beta" across regions, ranging from a low of 0.622 for Latin America to a high of 1.926 for the Middle East, represented in our portfolio simply by four Turkish firms and so should not be taken as typical. ${ }^{21}$ The second lowest "beta" was estimated for Italy, 0.663, and the second highest for neighboring Germany, 1.165. Evidently geographic proximity does not translate to similarity in equity betas, at least not for our portfolio. South East Asia is closest to the pooled "beta" at 0.842 .

Turning now to interest rate sensitivity, recall that the MGE of the interest rate variable for the heterogeneous model is -2.990 , meaning an increase in interest rates has an adverse effect on firm

\footnotetext{
${ }^{21}$ The Middle East region did not include a domestic equity variable, so all return equations for the Turkish firms include the foreign equity return variable, $\Delta q_{i, t+1}^{*}$, for $i=$ Turkey.
} 
returns. This coefficient is not significant for either of the pooled models, $\mathrm{M}_{1}$ and $\mathrm{M}_{2}$, and it has the wrong sign. Allowing for variation across sectors, $\mathrm{M}_{3}$, results in significant and negative coefficients for FIRE, -5.590, and Wholesale \& Retail Trade, -3.711. Just one of the positive coefficients is significant: 3.402 for Non-durable Manufacturing. Similar results are obtained in the case of Model $\mathrm{M}_{4}$, where the interest rate variable is statistically significant with a correct sign only in case of US firms (-5.974), the Turkish firms in the Mid East region (-6.676), and South East Asia (-5.454). Only one of the positive estimates is statistically significant, although it is small, and that is for Latin America, 0.111.

The coefficient on oil price changes is significant and positive for both pooled models, $\mathrm{M}_{1}(0.063)$ and $\mathrm{M}_{2}$ (0.064), echoing the MGE for the heterogeneous model $\mathrm{M}_{0}$ (0.145). Recall, however, that the MGE of the sub-groups with positive and negative coefficients were also significant, suggesting that firm-level heterogeneity for this factor loading may be particularly important. When grouping by industry or region, however, only the positive coefficients are significant. Indeed, in the indeustry/sector model, the coefficient of the oil price variable is significant only for Communication, Electric \& Gas, at 0.113. In the regional model it is significant for several regions, including the U.S. (0.076), Germany (0.230), Mid East (2.341), which is not surprising, and Latin America (1.035), although the oil exporter Venezuela is not part of our Latin American region.

From a model fit perspective, as measured by $\bar{R}^{2}$, regional heterogeneity is more important than industry heterogeneity: $\bar{R}^{2}=0.171$ for the former and 0.151 for the latter. Both are preferred to just adding firm fixed effects to the pooled model: the $\bar{R}^{2}$ for $\mathrm{M}_{2}$ is 0.148 . By comparison, the average $\bar{R}^{2}$ for the heterogeneous model $\mathrm{M}_{0}$ is 0.201 ; see Table 4 .

Finally, we computed the average pair-wise cross-sectional return correlation across all firms in our portfolio as well as of the residuals for each of the return specifications, $\mathrm{M}_{0}$ through $\mathrm{M}_{4}$. The average pair-wise cross-sectional return correlation turns out to be about $11.2 \%$. While this may seem low for equity returns, note first that returns are measured at relatively low frequency - quarterly, and second that our portfolio is quite well diversified, with firms from 21 countries grouped into 10 regions, and across all major industry groups. The three factors used in the five model specifications are able to absorb a significant amount of the cross-firm dependence: the average residual correlation ranges from $3.7 \%$ to $4 \%$ across the models.

Another consideration in our comparative analysis is the extent to which the five alternative parametric specifications affect cross section correlations of the simulated returns. Since all the five models are based on the same set of observed factors, cross section correlations of the simulated returns will be affected significantly by parameter heterogeneity only if the differences of parameters across firms are systematic. In the case of pure random differences across slopes, it is easily seen that all specifications would imply similar degrees of error cross correlations, and this is in fact true in the present application. 


\section{Simulated Credit Loss Distributions}

\subsection{Unconditional and Conditional Loss}

With the estimated GVAR model serving as the macroeconomic scenario generator and the fitted multi-factor regressions as the linkage between firms and the global economy, we simulated loss distributions one year ahead. We do this by first forecasting, out-of-sample, the evolution of the 64 GVAR risk factors, using those forecasts and the risk factor loadings or return regression coefficients to compute firm return forecasts, and then seeing if that return forecast falls below the default threshold. A one year horizon is typical for credit risk management and thus of particular interest. We carried out 200,000 replications for each scenario, baseline as well as shock scenarios, using Gaussian innovations.

The estimation period ends in 1999Q1, and we generate the loss distribution out of sample over one year to the end of 2000Q1. The year over which the loss distribution is simulated turned out to have been relatively benign for the firms in our portfolio when compared to the sample period which we use to compute unconditional parameters such as expected returns and return volatilities. The unconditional one-year portfolio return (i.e. the exposure weighted average return of all firms in the portfolio) is $14.67 \%$, whilst using the specification for the fully heterogeneous model $\mathrm{M}_{0}$, the conditional portfolio return projected for the forecast year is $37.78 \%$. This is reflected in the difference between conditional and unconditional portfolio default (the same as expected loss, EL, under the maintained assumption of no loss recovery). Recall from Table 3 that unconditional EL is $0.294 \%$, but conditional EL under the default threshold $(\lambda)$ identifying assumption (8) is $0.096 \%$, and under the same distance to default $(D D)$ assumption (5) is $0.089 \% .^{22}$ When we compare the analytical to the simulated conditional portfolio default or expected loss, they are very close: $0.096 \%$ for same $\lambda$ and $0.087 \%$ for same $D D$.

Fixing $D D$ to be the same across firms by rating also fixes the unconditional default probability; the two are isomorphic. Conditioning on return forecasts updates those probabilities. Fixing the default threshold $\lambda$ by rating, however, allows for heterogeneity in the unconditional default probabilities; they just need to be the same on average (see the discussion in Section 2.2). Those, in turn, may be updated over time as conditioning information is incorporated. This firm-level heterogeneity in unconditional probabilities of default $(P D)$ can make a big difference empirically, as is seen in Figure 1 which displays a scatter plot of unconditional (horizontal axis) and conditional (vertical axis) one-year $P D s$ for the 243 firms in the portfolio. The top panel is for the same default threshold $(\lambda)$ by credit rating for all firms, while the bottom panel is for the same distance to default $(D D)$ by credit rating for all firms. The axes on both charts are scaled to be directly comparable. We see immediately in the top panel that conditional and unconditional $P D$ s are not only widely

\footnotetext{
${ }^{22}$ The differences between the latter two estimates are due to rounding error arising from the inverse normal transform on very small probabilities.
} 
dispersed, reflective of the underlying firm level heterogeneity, but also highly correlated $(\rho=0.961)$. By contrast the same $D D$ by rating chart (bottom panel) has both the unconditional and conditional $P D$ s tightly clustered in a narrow range. As there are six credit ratings represented in this study, so we see six vertical lines, where the vertical scatter represents the variation in conditional $P D$ by rating (all having the same unconditional $P D$, of course) resulting in a lower correlation between unconditional and conditional $P D$ s $(\rho=0.790)$. In contrast to same $\lambda$, the $P D$ s implied by same $D D$ change dramatically through conditioning. (or updating). These differences will become more explicit and pronounced in the loss distributions across the model specifications, an issue we address next.

[Insert Figure 1 about here]

\subsection{Model Heterogeneity and Baseline Losses}

In moving from the most homogeneous model $\mathrm{M}_{1}$ to $\mathrm{M}_{2}$, we add heterogeneity in the conditional mean by allowing for firm fixed effects, as well as heterogeneity in the unconditional probability of default, namely by introducing credit rating information. To isolate the effects of these relaxations of the homogeneity restrictions, we add an intermediate model which augment model $\mathrm{M}_{1}$ with credit rating information. Consequently we denote $\mathrm{M}_{1 a}$ to be the homogeneous model without the use of rating information, and $\mathrm{M}_{1 b}$ the homogeneous model that allows for credit ratings in determination of the default thresholds.

Table 6 gives summary statistics for the baseline (i.e. no risk factor shocks) loss distribution for all models, with the top panel imposing the same threshold, $\lambda$, identifying restriction, and the bottom panel the same distance to default, $D D$, restriction. We show the first four moments as well as three tail quantiles or values-at-risk (VaR): 99.0\%, 99.5\% and 99.9\%, corresponding to levels commonly used by risk managers, and in the last case, the risk tolerance level of the New Basel Capital Accord (BCBS (2004)).

\section{[Insert Table 6 about here]}

Looking first at the top panel, EL and UL vary significantly across the different specifications, both increasing as we increase model heterogeneity. However, as shown in Hanson, Pesaran and Schuermann (2005), it is important that the differences in EL's across the different portfolios are taken into account, before implications of heterogeneity for unexpected losses can be evaluated. There is no obvious way that this can be done. Here we normalize risk, whether measured by unexpected loss (UL) or VaR, by EL. We shall refer to these as EL multiples.

The results in Table 6 show that it takes about 21 EL multiples to obtain one standard deviation of losses for the most homogeneous model $\mathrm{M}_{1 a}$, just 11 for the industry model $\mathrm{M}_{3}$, and only 2.5 for the fully heterogeneous model $\mathrm{M}_{0}$. The third and fourth moments, skewness and kurtosis 
respectively, also decline when more heterogeneity is allowed for. Imposing homogeneity results in overly skewed and fat-tailed loss distributions. This point becomes quite clear when looking at the 99.9\% VaR: model $\mathrm{M}_{1 a}$ and $\mathrm{M}_{1 b}$ have EL multiples in excess of 300, while the regional model $\mathrm{M}_{4}$ has a multiple of only 54 and the fully heterogeneous model $\mathrm{M}_{0}$ only 21 , less than one-tenth of the most homogeneous model.

Adding credit ratings to the homogeneous specification, model $\mathrm{M}_{1 b}$, results in noticeable drop in EL multiples: UL/EL drops from 20.8 to 17.1, and 99.9\% VaR from 382 to 305. Adding firm fixed effects, model $\mathrm{M}_{2}$, does not help; in fact risk seems to increase slightly. We need to allow for variation in factor loadings, either by industry, model $\mathrm{M}_{3}$, or region, model $\mathrm{M}_{4}$, before EL multiples decline further. A similar pattern holds when looking at value at risk. In this regard regional heterogeneity seems to play a more important role than industry heterogeneity, perhaps not surprising given the international nature of this portfolio. ${ }^{23}$

Turning to the bottom panel, where the loss distributions are simulated under the same $D D$ identifying restriction, differences across model specifications are much more muted. The results for the heterogeneous model $\mathrm{M}_{0}$ are broadly in line with its same $\lambda$ counterpart in the top panel (EL and UL, and VaR are similar). However, EL decreases as we increase the degree of parameter heterogeneity. Moreover, there is little difference in EL multiples, whether looking at loss volatility (UL) or VaR. In fact, the results would suggest that increased heterogeneity actually increases risk: $\mathrm{UL} / \mathrm{EL}$ for $\mathrm{M}_{1 a}$ is 1.4 and for $\mathrm{M}_{0}$ is 3.0. Further, $99.9 \%$ VaR, normalized by EL, is 11 for $\mathrm{M}_{1 a}$ and 28 for $\mathrm{M}_{0}$. In light of these results, and the previous discussion of unconditional and conditional $P D$ s, in the remaining analysis we focus on the same threshold $(\lambda)$ identifying restriction.

Before proceeding to the shock scenarios, it may be of interest to compare the simulated UL to that implied by the Vasicek model as discussed in Section 3. This asymptotic expression, given in (21), is driven by the average default rate across the portfolio, $\pi$, and the default correlation, $\rho^{*}$, itself a function of $\pi$ and the average return correlation of the firms in the portfolio, $\rho$, which is $11.2 \%$ for our portfolio; see (20) in Section 3. Thus using the unconditional portfolio default rate from Table $3, \pi=0.294 \%$, this yields a default correlation of $\rho^{*}=0.470 \%$ and an asymptotic $U L=\sqrt{\pi(1-\pi) \rho^{*}}=0.371 \%$, which is above the simulated UL of all models. However, those simulated ULs are conditional, not unconditional, and if we substitute the simulated (conditional) EL (which, under the maintained assumption of no loss recovery, is identical to $\pi$ ), all asymptotic UL values are below their simulated counterparts, as they should be, assuming that the average return correlation $\rho$ remains unchanged. For example, in the case of model $\mathrm{M}_{0}, \pi=0.094 \%$, so that $\rho^{*}=0.208 \%$. In that case asymptotic $U L=0.140 \%$ which is below the simulated UL of $0.239 \%$. The difference is clearly due to granularity, an issue we pick up in Section 6.5 below.

\footnotetext{
${ }^{23}$ We tried a different industry specification using 10 instead of 6 groups to match the number of parameters in the regional model (there are 10 regions). This did not change our conclusions.
} 
[Insert Figure 2 about here]

In Figure 2 we compare the simulated loss distributions across model specifications. The top panel displays the $20 \%$ tail $\left(80^{t h}\right.$ percentile and beyond) and the bottom panel focuses on the $5 \%$ tail. The extreme skewness and fat-tailedness of the more restricted models becomes apparent. We see that the fully heterogeneous model in particular accumulates losses much earlier in the distribution, already by about the $82^{\text {nd }}$ percentile, than the other models. Significant losses are not seen until about the $95^{\text {th }}$ percentile for the regional model $\mathrm{M}_{4}$, not until after the $97^{\text {th }}$ percentile for the industry model $\mathrm{M}_{3}$, and well beyond the $99^{\text {th }}$ percentile for all other models.

\subsection{Model Heterogeneity and Risk Factor Shocks}

One of the main advantages of our conditional modeling approach is that it allows us to consider the impact of different macroeconomic or risk factor shock scenarios. The ability to conduct shock scenario analysis with observable risk factors is clearly important for policy analysis, be it business or public policy.

Recall that the risk factors in the firm return models are equity returns, interest rates and oil prices. In addition we shall explore the impact of business cycle heterogeneity across different countries by considering shocks to real output, which (as noted earlier) can influence the loss distributions indirectly through their contemporaneous correlations with equity returns and interest rates. Accordingly we examined the following equiprobable scenarios, though others are possible, of course: ${ }^{24}$

- a $\pm 2.33 \sigma$ shock to real U.S. equity, corresponding to a quarterly change of $\pm 14.28 \%$ from the baseline forecast, ${ }^{25}$

- $\mathrm{a}+2.33 \sigma$ shock to the German short term interest rate, corresponding to a quarterly rise of $0.33 \%$,

- a $-2.33 \sigma$ shock to real U.S. output, corresponding to a quarterly drop of $1.85 \%$.

In order to learn more about the tail properties of the various loss distributions, we also consider an extreme stress scenario for the U.S. equity market as reported in PSTW, namely an adverse shock of $8.02 \sigma$. This corresponds to a quarterly drop of $49 \%$ which is the largest quarterly drop in the S\&P 500 index since 1928, and that occurred over the three months to May of 1932. Finally, we include an intermediate negative equity shock of $-5 \sigma$ which corresponds to a quarterly decline

\footnotetext{
${ }^{24} 2.33 \sigma$ corresponds, in the Gaussian case, to the $99 \%$ Value-at-Risk (VaR), a typical benchmark in risk management.

${ }^{25}$ Relative to historic averages, this shock corresponds to a rise (drop) of $17.95 \%$ (11.35\%), computed as $\exp (2.23 \% \pm 14.28 \%)-1$.
} 
of $30.64 \%$. Details of how the macroeconomic shocks are generated and how they feed through firm returns to the loss distribution can be found in PSTW.

[Insert Table 7 about here]

We start the discussion with a $\pm 2.33 \sigma$ shock to real U.S. equity under the same threshold, $\lambda$, restriction, summarized in Table 7 . For each model we repeat the baseline results for ease of comparison and display the percentage increase (decrease) from that baseline of EL, UL and 99.9\% VaR. For each model, the percentage increase in EL and UL arising from the adverse shock is always larger than the corresponding decline in losses due to a benign shock. Consider model $\mathrm{M}_{1 a}$ : EL (UL) increases by $88 \%$ (73\%) under the adverse shock and decreases by $67 \%$ (48\%) under the benign shock. The size of those impacts declines as we allow for more heterogeneity. The regional model $\mathrm{M}_{4}$, for instance, shows an increase in EL (UL) of $151 \%$ (42\%) from the adverse shock against a decline of $46 \%$ (29\%) from the benign shock. The smallest impact can be seen from the most heterogeneous model, $\mathrm{M}_{0}$ : the adverse shock increases EL (UL) by $51 \%$ (31\%) and the benign shock decreases EL (UL) by $31 \%$ (21\%).

This asymmetric and non-proportional response of credit losses to symmetric shocks is due to the nonlinearity of the credit risk model. When going to the tails of the loss distribution, however, only the fully heterogeneous model $\mathrm{M}_{0}$ maintains this asymmetric response. For all other model specifications, the reduction in $99.9 \%$ VaR arising from the benign shock is larger than the corresponding increase in $99.9 \%$ VaR due to the adverse shock. Thus, by imposing homogeneity, not only are the relative loss responses exaggerated (all the percentage increases and decreases are larger for the restricted than for the unrestricted model), but perceived reduction in risk in the tail of the loss distribution tends to be overly optimistic.

Finally, note that an adverse shock results in less skewed and fat-tailed loss distributions, relative to their respective baselines, across all models, and conversely a benign shock renders them more extreme. The adverse (benign) shock results in more (fewer) firms defaulting systematically due to the displacement of expected (i.e. forecast) returns, before any additional idiosyncratic risk is accounted for. As a result an adverse (benign) shock shifts probability mass of the loss distribution closer to (farther from) the mean. The effects of the shocks on the shape of the loss distribution is quite large for relatively homogeneous models, and much more modest for heterogeneous ones. For instance, the skewness (kurtosis) for $\mathrm{M}_{1 a}$ decreases to 19.4 (537) under the adverse shock compared to the baseline, 29.4 (1200), but increases to 38.0 (1652) under the benign shock. By contrast, the skewness and kurtosis decreases to 5.1 and 37, respectively, for the regional model, $\mathrm{M}_{4}$, under the adverse shock scenario as compared to the baseline values of 6.5 and 56, but increases to 8.4 and 86 under the benign shock scenario, respectively. The relative impact is, of course, even smaller for the fully heterogeneous model, $\mathrm{M}_{0}$. 
The evidence thus far suggests that heterogeneity is important in controlling risk both under a baseline forecast and under shock scenarios. Allowing for regional heterogeneity appears to be more important than allowing for industry or sector heterogeneity. Both the baseline and shockconditional loss distributions seem to change noticeably with the addition of heterogeneous factor loadings, i.e. starting with model $\mathrm{M}_{3}$. However, the biggest marginal change arises when allowing for full heterogeneity with model $\mathrm{M}_{0}$.

Next we consider an adverse shock to German interest rates. Naturally we could have shocked interest rates of other countries, e.g. the U.S., but since we already have other U.S.-based shock scenarios, we wanted to broaden the discussion by considering shocks to other countries' macroeconomic factors. Interest rate shocks are of particular interest in our modeling context because the corresponding factor loading is positive, but insignificant, for the pooled models $\mathrm{M}_{1}$ and $\mathrm{M}_{2}$, on average negative and significant for the heterogeneous model $\mathrm{M}_{0}$, and rather mixed for the industry and regional models, $\mathrm{M}_{3}$ and $\mathrm{M}_{4}$.

[Insert Table 8 about here]

The loss simulation results are summarized in Table 8. Compared with adverse U.S. equity shocks, the impact on credit losses due to an equiprobable adverse shock to German interest rates is more modest. EL increases on average by only about $24 \%$, UL by only $12 \%$, and $99.9 \%$ VaR by around $5 \%$. Here too we see a similar model ranking as before, with the most homogeneous model $\mathrm{M}_{1 a}$ being the most shock sensitive, at least when measured by EL and UL impact, and the most heterogeneous model $\mathrm{M}_{0}$ the least shock sensitive. The impact on on $99.9 \%$ VaR is modest across all models, and given parameter uncertainty, broadly similar across the different model specifications.

Even though the factor loading on interest rates is positive, albeit small and not significant, for the pooled models $\mathrm{M}_{1 a}, \mathrm{M}_{1 b}$ and $\mathrm{M}_{2}$, losses still increase in reaction to an adverse interest rate shock. Because of the complicated inter-dependencies that exist in the GVAR model, shocking one of the factors will potentially impact all the other 62 factors. As a result the overall effect of the shock on the loss distribution need not have the same sign as the coefficient of the factor in the return equation. Consequently an adverse interest rate shock may have the counter-intuitive benign direct effect on firm returns in the pooled return regressions, but the intuitive adverse indirect effects through the equity return factor.

With this in mind we consider the effects of an adverse shock to real U.S. output. Recall that output does not enter the firm return regressions; however, shocks in output may enter indirectly through the other variables such as interest rates and equity prices. We summarize those results in Table 9 and notice immediately that the changes from the baseline are of the wrong sign but quite small and are unlikely to be statistically significant. One year after the shock, credit losses are projected to actually decline somewhat. Average decline in EL across models is about 5\%, the decline in UL is about $3 \%$, and the decline in $99.9 \%$ VaR about $2 \%$ relative to the baseline loss 
distribution. In Section 6.4 below we explore whether including output directly in the firm-specific return regressions makes any difference.

[Insert Table 9 about here]

Finally, we consider the effect of extreme shocks to the resulting distribution of credit losses under different model specifications. Table 10 presents results from two different U.S. real equity shock scenarios: $-5.00 \sigma$ in Panel A and $-8.02 \sigma$ in Panel B, the latter matching the largest quarterly drop in the $\mathrm{S} \& \mathrm{P} 500$ index since 1928. To be sure, a shock as extreme as $-8.02 \sigma$ is, of course, outside the bounds of the estimated model. It would be unreasonable to believe that such a large shock would not result in changes to the underlying parameters. However, it is still instructive to examine the impact of an extreme shock, one way one might stress a credit risk model. Moreover, $5 \sigma$ events are more common at higher frequencies than the quarterly data we have available to us, and in this way our results will likely underestimate the true loss outcomes.

[Insert Table 10 about here]

Under the $-5 \sigma$ shock scenario, shown in Panel A, increases in expected losses across models range from eleven-fold $(1035 \%)\left(\mathrm{M}_{2}\right)$ to nine-fold $(794 \%)\left(\mathrm{M}_{1 a}\right)$ to just $154 \%\left(\mathrm{M}_{0}\right)$. UL increases for the same models are about three and a half-fold for $\mathrm{M}_{1 a}(244 \%)$ and $\mathrm{M}_{2}(266 \%)$ and not quite double for $\mathrm{M}_{0}(85 \%)$. Differences in the tail impact at the $99.9 \%$ level are not as extreme: $150 \%$ for $\mathrm{M}_{1 a}, 107 \%$ for $\mathrm{M}_{2}$ and $83 \%$ for $\mathrm{M}_{0}$. But the broad pattern observed so far holds: the more restrictive (homogeneous) the model, the more sensitive it reacts to shock scenarios.

[Insert Figure 3 about here]

As the shock becomes more extreme to $-8.02 \sigma$, see Panel B in Table 10, the resulting loss distribution for all models becomes less skewed and fat-tailed, as measured by kurtosis. To see this graphically we generated density plots for model $\mathrm{M}_{0}$, presented in Figure 3 . In the top panel we display the simulated loss densities for model $\mathrm{M}_{0}$ for the baseline, the symmetric and two severe shocks to U.S. real equity prices. To make it easier to see some of the features of the shock-conditional distributions, the positive shock density is not shown in the bottom panel.

\subsection{Business Cycle Shocks: An Alternative Model Specification}

The return regressions used in the above simulation exercises do not select the real output growth as a risk factor. As noted earlier this might not be that surprising as the effects of business cycle fluctuations on firm returns could have already been incorporated indirectly through market returns. It is, however, possible that the factor selection and the subsequent model estimation 
could have been biased due to the use of country-specific asset return variables, particularly in the case of countries with relatively small asset markets. ${ }^{26}$

With this in mind, and following the work of Kapetanios and Pesaran (2004), we proceeded to estimate an alternative version of the fully heterogeneous model which includes a global equity return, $\Delta \bar{q}_{t+1}$, defined as the cross-sectional average of all equity indices in the GVAR model instead of the country-specific market returns, $\Delta \tilde{q}_{i, t+1}$ used in (35). We then run this version of the return regression augmented with real output growth for region $i$, denoted by $\Delta y_{i, t+1}$, and the other variables, namely changes in interest rates $\left(\Delta \rho_{i, t+1}\right)$ and oil prices $\left(\Delta p_{t+1}^{o}\right):{ }^{27}$

$$
r_{j i s, t+1}=\alpha_{j i s}+\beta_{1, j i s} \Delta \bar{q}_{t+1}+\beta_{2, j i s} \Delta \rho_{i, t+1}+\beta_{3, j i s} \Delta p_{t+1}^{o}+\beta_{4, j i s} \Delta y_{i, t+1}+\xi_{j i s, t+1} .
$$

The MGE results for the alternative specification (40) using PPP weights are given in Table 11. These new estimates attribute a smaller effect to market returns with the average market "beta" falling from 0.918 to 0.780 and the interest rate effects rising (in absolute value) from -2.99 to -4.236. The average effect of real output growth on firm returns is also statistically significant and has the correct sign, which contrasts the earlier results based on country-specific equity market returns. The average effects of oil price changes, although still positive, are no longer statistically significant. The change in the estimates as a result of using $\Delta \bar{q}_{t+1}$ instead of $\Delta \tilde{q}_{i, t+1}$ are in line with a priori expectations and could be explained by a positive correlation between the country-specific market returns and the errors in the firm-specific return regressions. This is also reflected in the estimates of the in-sample fit of the return regressions where the avg. $\bar{R}^{2}$ declines from 0.201 to 0.103 as we move from $\Delta \tilde{q}_{i, t+1}$ to $\Delta \bar{q}_{t+1}$. The decline in the fit is quite substantial and could be an important consideration in the choice between the alternative specifications, although any simultaneity arising from inclusion of $\Delta \tilde{q}_{i, t+1}$ could in itself result in an upward bias in the avg. $\bar{R}^{2}$.

[Insert Table 11 about here]

Bearing in mind the uncertainty associated with these alternative specifications, the loss simulations based on the new return regressions for the baseline scenario as well as for the $2.33 \sigma$ shock scenarios are summarized in Table 12. These simulations can be viewed as providing a check on the robustness of the loss simulation results obtained so far. Baseline loss behavior is only somewhat different from $\mathrm{M}_{0}$ (see last row of Table 6, top panel), but importantly it is closer than any of the

\footnotetext{
${ }^{26}$ Recall that the estimates of the output effects are obtained by regression of firm-specific returns on the market returns, output growth and other variables such as changes in the interest rates and oil prices. Since market returns are in effect weighted averages of the firm-specific returns, the return regressions could yield biased estimates if the market return happens to be based on a relatively few firms.

${ }^{27}$ This cross-sectional average may be either equal weighted or PPP-weighted. We experimented with both. In the latter case we used PPP weights from 1996, the same weights used in the GVAR to construct regions from countries. There were little differences in the result, and in what follows we focus on the estimates based on the PPP-weighted global real equity index.
} 
other restricted models, even though their in-sample goodness of fit was higher. When we examine the impact of shocks, even though real output now directly enters the firm return regressions, the impact of an adverse shock to real U.S. output growth is very similar to the previous specification: it is both small and of the wrong sign. Meanwhile the impact of the other shocks are similar in this as in the original specification.

[Insert Table 12 about here]

Although the average loading on output is positive, statistically significant and large at 0.7 , it turns out that about half (45\%) of the firms actually have a negative coefficient (loading) on output. Indeed when we look at the MGE of the positive and negative subsets, they are both significant. Hence it is not surprising that for our portfolio, the net impact of an adverse shock to output is about zero. Of course, if the portfolio were comprised only of firms with a positive loading, credit losses would likely increase in the event of an adverse output shock.

As far as loss distributions are concerned, our overall conclusions seem to be robust to the choice of the firm-specific return regressions.

\subsection{Idiosyncratic Risk and Granularity}

Portfolio-level results of credit risk models such as those discussed in Vasicek (1987, 2002) assume that the portfolio is sufficiently large that all idiosyncratic risk has been diversified away. More generally we consider a credit portfolio composed of $N$ different credit assets such as loans, each with exposures or weights $w_{i}$, for $i=1,2, . ., N$, such that the granularity condition (22) holds. Recall that a sufficient condition for (22) to hold is given by $w_{i}=O\left(N^{-1}\right) .{ }^{28}$ The lower the average firm return correlation, the greater the potential for diversification, but a larger $N$ is required to attain that limit than if correlations are lower. A common rule of thumb for return diversification of a portfolio of equities is $N \approx 50$. But as seen in Section 6.2 , default correlations are much lower than return correlations, meaning that more firms are needed to reach the diversification limits of credit risk.

Thus it seems reasonable to ask if a portfolio of $N=243$ is large enough to diversify away the idiosyncratic risk. To answer this question we used an empirical version of the one-factor Vasicek model described in Section 3 and analyzed the impact of increasing $N$ on simulated compared to analytic (asymptotic) unexpected loss (UL). For simulation purposes, Vasicek's model takes the following form:

$$
r_{j, t+1}=\bar{r}+\sigma_{f} f_{t+1}+\sigma_{\varepsilon} \varepsilon_{j, t+1}
$$

\footnotetext{
${ }^{28}$ Conditions (22) on the portfolio weights was in fact embodied in the initial proposal of the New Basel Accord in the form of the Granularity Adjustments which was designed to mitigate the effects of significant single-borrower concentrations on the credit loss distribution. See Basel Committee (2001, Ch.8).
} 
where $\bar{r}=\sum_{t=1}^{T} \sum_{j=1}^{N} r_{j t} / N T$,

$$
\left(\begin{array}{c}
\varepsilon_{j, t+1} \\
f_{t+1}
\end{array}\right) \sim i . i . d . N\left(\mathbf{0}, \mathbf{I}_{2}\right),
$$

$\mathbf{I}_{2}$ is a 2-dimensional identity matrix, $\rho=\sigma_{f}^{2} /\left(\sigma_{f}^{2}+\sigma_{\varepsilon}^{2}\right)$, and $\sigma_{f}^{2}$ is the variance of the "market" return. These parameters can be estimated as

$$
\hat{\sigma}_{f}^{2}=\frac{\sum_{t=1}^{T}\left(\bar{r}_{t}-\bar{r}\right)^{2}}{T-1}, \bar{r}_{t}=\sum_{j=1}^{N} r_{j t} / N,
$$

and

$$
\hat{\sigma}_{\varepsilon}^{2}=\frac{\sum_{t=1}^{T} \sum_{j=1}^{N}\left(r_{j t}-\bar{r}_{t}\right)^{2}}{N T-2} .
$$

Loss is given by (19) with the return default threshold given by

$$
\lambda=\bar{r}+\sqrt{\sigma_{f}^{2}+\sigma_{\varepsilon}^{2}} \Phi^{-1}(\pi)
$$

For our portfolio, for the one-year horizon we have the following parameter values: $\bar{r}=13.356 \%$, $\hat{\sigma}_{f}=11.230 \%, \hat{\sigma}_{\varepsilon}=34.856 \%, \hat{\pi}=0.294 \%$, so that the implied average return correlation $\rho=$ $9.404 \%$, with an associated default correlation of $\rho^{*}=0.369 \% .{ }^{29}$ Substituting these values in (44) obtains a one-year return default threshold of $-87.51 \%$, meaning that any firm that experiences a one-year return worse than $-87.51 \%$ would default.

Calibrating the Vasicek's model to these parameters we simulated losses assuming different portfolio granularity, ranging from 119 to 10,000 firms. To be sure, all firms share the same draw of the systematic factor $f$ and the same default threshold lambda, while each firm carries idiosyncratic risk (reflected by firm-specific draws from $\varepsilon_{j, t+1} \backsim N(0,1)$ ). Idiosyncratic risk should diversify away, with the simulated UL approaching the analytic UL as the number of firms increases.

The results are summarized in Table 13. The result for $N=119$ relates to the number of firms in the PSTW portfolio. By more than doubling $N$ we cut idiosyncratic risk nearly in half. But to come within $3 \%$ of the asymptotic UL of the portfolio, more than 5,000 firms are needed! Thus credit portfolios or credit derivatives such as CDOs which contains rather fewer number of firms will likely still retain a significant degree of idiosyncratic risk, an observation also made by Amato and Remolona (2004).

[Insert Table 13 about here]

\footnotetext{
${ }^{29}$ The relationship between $\rho$ and $\rho^{*}$ is given by $(20)$.
} 


\section{Concluding Remarks}

In this paper we have made use of a conditional credit risk model with observable risk factors, developed in Pesaran, Schuermann, Treutler and Weiner (2004), to explore several dimensions of credit risk diversification: across industries (sectors) and across different countries or regions, either in a relatively restrictive fixed effects return specifications, or by allowing for full firm-level heterogeneity. Specifically, we fix the number of risk factors - there are three: market equity returns and changes in domestic interest rates and oil prices - and only vary the degree of parameter heterogeneity across models. We find that full firm-level parameter heterogeneity matters a great deal for capturing differences in simulated credit loss distributions. Expected loss (EL) increases as more heterogeneity is allow for. However, unexpected losses, normalized by EL, decline dramatically. Moreover, imposing homogeneity results in overly skewed and fat-tailed loss distributions.

These differences become more pronounced in the presence of shocks to systematic risk factors. The most restricted model which imposes the same factor sensitivities across all firms is overly sensitive to such shocks, and thus failing to properly account for parameter heterogeneity could result in too much implied risk capital. Allowing for regional parameter heterogeneity seems to better approximate the loss distributions generated by the fully heterogeneous model than allowing just for industry heterogeneity.

The results raise a number of questions and issues that merit further exploration. Our portfolio, by virtue of being allocated across 21 countries in 10 regions, is already quite diversified as evidenced by an average cross-sectional pair-wise return correlation of $11.2 \%$. Concentrating all of the nominal exposure into just one region or one industry would undoubtedly have significant impact on the resulting loss distribution, in addition to yielding differences across models. A difficulty one would quickly encounter in exploring this problem are the rating or default probability differences across those dimensions. The average rating in the U.K., for instance, is much higher than for the Latin American obligors, especially if one follows the rule that an obligor rating cannot exceed the sovereign rating. ${ }^{30}$

It is also worth exploring the impact of fat-tailed innovations on the resulting loss distributions. The current application is limited to the double-Gaussian assumption (both idiosyncratic and systematic innovations are normal), but it seems reasonable to relax this assumption by considering, say, draws from Student-t distributions with low degrees of freedom.

\footnotetext{
${ }^{30}$ This rule seems quite reasonable when one considers debt denominated in, say, USD (or euros), but perhaps less so if the debt is exclusively in the local currency.
} 


\section{References}

[1] Altman, Edward I. (1968). "Financial Ratios, Discriminant Analysis and the Prediction of Corporate Bankruptcy." Journal of Finance 20, 589-609.

[2] Amato, Jeffrey D., and Craig H. Furfine. (2004). "Are Credit Ratings Procyclical?" Journal of Banking \& Finance 28, 2641-2677.

[3] Amato, Jeffrey D. and Eli Remolona. (2004). "The Pricing of Unexpected Losses." Paper presented at the Workshop on the Pricing of Credit Risk, BIS, September 2004.

[4] Bangia, Anil, Francis X. Diebold, André Kronimus, Christian Schagen and Til Schuermann (2002). "Ratings Migration and the Business Cycle, With Applications to Credit Portfolio Stress Testing." Journal of Banking 83 Finance 26, 235-264.

[5] Basel Committee on Banking Supervision (2001). "The New Basel Capital Accord." $<$ http://www.bis.org/publ/bcbsca03.pdf $>$, January.

[6] Basel Committee on Banking Supervision (2004). "International Convergence of Capital Measurement and Capital Standards: A Revised Framework." $<$ http://www.bis.org/publ/bcbs107.htm>, June.

[7] Black, Fischer, and John C. Cox (1976). "Valuing Corporate Securities: Some Effects of Bond Indenture Provisions." Journal of Finance 31, 351-367.

[8] Cantor, Richard and Frank Packer. (1995). "The Credit Rating Industry." Journal of Fixed Income, December, 10-34.

[9] Dees, S., F. di Mauro, M. H. Pesaran and L. V. Smith (2005), "Exploring the International Linkages of the Euro Area: A Global VAR Analysis", CESifo Working Paper No. 1425. Presented at CESifo Area Conference on Macro, Money and International Finance, February 2005 .

[10] Duffie, Darrell and David Lando. (2001). "Term Structures of Credit Spreads with Incomplete Accounting Information." Econometrica 69, 633-664.

[11] Garbade, Kenneth. (2001). Pricing Corporate Securities as Contingent Claims, Cambridge, MA: MIT Press.

[12] Gordy, Michael B. (2000). "A Comparative Anatomy of Credit Risk Models." Journal of Banking \& Finance 24 (1-2), 119-149.

[13] Gordy, Michael B. (2003). "A Risk-Factor Model Foundation for Ratings-Based Bank Capital Rules." Journal of Financial Intermediation 12, 199-232. 
[14] Hanson, Samuel G., M. Hashem Pesaran and Til Schuermann. (2005). "Scope for Credit Risk Diversification." Wharton Financial Institutions Center Working Paper \#05-05.

[15] Hsiao, C. and Pesaran, M. H. (2004). "Random Coefficient Panel Data Models." CESifo Working Paper Series No. 1233; IZA Discussion Paper No. 1236.

[16] Jafry, Yusuf and Til Schuermann. (2004). "Measuring, Estimating and Comparing Credit Migration Matrices." Journal of Banking \& Finance 28, 2603-2639.

[17] James, Christopher and David C. Smith. (2000). "Are Banks Still Special? New Evidence on their Role in the Corporate Capital-Raising Process." Journal of Applied Corporate Finance $13,52-63$.

[18] Kapetanios, George and M. Hashem Pesaran (2004), "Alternative Approaches to Estimation and Inference in Large Multifactor Panels: Small Sample Results with an Application to Modelling of Asset Returns," CESifo Working Paper Series No. 1416; available at http://www.econ.cam.ac.uk/faculty/pesaran/.

[19] Kealhofer, S. and M. Kurbat. (2002). "Predictive Merton Models." Risk February, 67-71.

[20] Lando, David. (2004). Credit Risk Modeling: Theory and Applications, Princeton, NJ: Princeton University Press.

[21] Lando, David and Torben Skødeberg. (2002). "Analyzing Ratings Transitions and Rating Drift with Continuous Observations." Journal of Banking \& Finance 26 (2-3), 423-444.

[22] Leland, Hayne E. and Klaus Bjerre Toft. (1996). "Optimal Capital Structure, Endogenous Bankruptcy, and the Term Structure of Credit Spreads." Journal of Finance 51, 987-1019.

[23] Lennox, Clive (1999). "Identifying Failing Companies: A Re-Evaluation of the Logit, Probit and DA Approaches." Journal of Economics and Business 51, 347-364.

[24] Mella-Barral, Pierre and William Perraudin. (1997). "Strategic Debt Service." Journal of Finance $52(2), 531-556$.

[25] Merton, Robert C. (1974). "On the Pricing of Corporate Debt: The Risk Structure of Interest Rates." Journal of Finance 29, 449-470.

[26] Pesaran, M. Hashem, Til Schuermann, and Scott M. Weiner. (2004). "Modeling Regional Interdependencies using a Global Error-Correcting Macroeconometric Model.” (with discussion), Journal of Business 6 Economic Statistics 22, 129-162 and 175-181. 
[27] Pesaran, M. Hashem, Til Schuermann, Björn-Jakob Treutler and Scott M. Weiner. (2005). "Macroeconomics and Credit Risk: A Global Perspective." forthcoming, Journal of Money, Credit and Banking, available as Wharton Financial Institutions Center Working Paper \#03$13 \mathrm{~B}$.

[28] Pesaran, M.Hashem, Ron P. Smith. (1995). "Long-Run Relationships from Dynamic Heterogeneous Panels," Journal of Econometrics 68, 79-113.

[29] Pesaran, M.Hashem, Ron P. Smith and Kyung S. Im. (1996). "Dynamic Linear Models for Heterogenous Panels," in Lazlo Mátyás, and Patrick Sevestre. (eds.). The Econometrics of Panel Data. Dordrecht, The Netherlands: Kluwer Academic Publishers.

[30] Saunders, Anthony and Linda Allen. (2002). Credit Risk Measurement- New Approaches to Value at Risk and Other Paradigms, $2^{\text {nd }}$ Ed., New York: John Wiley \& Sons.

[31] Shumway, Tyler. (2001). "Forecasting Bankruptcy more Accurately: A Simple Hazard Model." Journal of Business 74, 101-124.

[32] Silverman, Bernard W. (1986). Density Estimation for Statistics and Data Analysis. New York, NY: Chapman \& Hall.

[33] Swamy, P.A.V.B. (1970). "Efficient Inference in a Random Coefficient Regression Model." Econometrica 38, 311-323.

[34] Vasicek, Oldrich. (1987). "Probability of Loss on Loan Portfolio." KMV Corp., San Francisco; available at www.kmv.com.

[35] Vasicek, Oldrich. (1991). "Limiting Loan Loss Distribution.” KMV Corp., San Francisco; available at www.kmv.com.

[36] Vasicek, Oldrich. (2002). "Loan Portfolio Value." Risk 15, 160-162. 
Table 1

\section{Countries/Regions in the GVAR Model}

\begin{tabular}{|l|l|l|l|}
\hline U.K. & Germany & Italy & France \\
\hline Western Europe & South East Asia & Latin America & Middle East \\
- Nelgium & - Indonesia & - Argentina & - Kuwait \\
- Spain & - Korea & - Brazil & - Saudi Arabia \\
- Switzerland & - Malaysia & - Chile & - Turkey \\
& - Singapore & - Mexico & \\
& - Thailand & & \\
\hline U.S.A. & Japan & China & \\
\hline
\end{tabular}


Table 2a

The Composition of the Sample Portfolio by Regions

\begin{tabular}{|l|c|c|c|c|}
\hline Region & $\begin{array}{c}\text { \# of } \\
\text { Obligors }\end{array}$ & $\begin{array}{c}\text { Equity Series } \\
\text { Quarterly }\end{array}$ & $\begin{array}{c}\text { Credit Rating } \\
\text { Range }\end{array}$ & $\begin{array}{c}\text { Portfolio } \\
\text { Exposure (\%) }\end{array}$ \\
\hline U.S.A. & 63 & $79 Q 1-99 Q 1$ & AAA to BBB- & 20 \\
U.K. & 24 & $79 Q 1-99 Q 1$ & AA to BBB+ & 8 \\
Germany & 21 & $79 Q 1-99 Q 1$ & AAA to BBB- & 10 \\
France & 14 & $79 Q 1-99 Q 1$ & AA to BBB & 8 \\
Italy & 10 & $79 Q 1-99 Q 1$ & A to BBB- & 8 \\
W. Europe & 24 & $79 Q 1-99 Q 1$ & AAA to BBB+ & 11 \\
Middle East & 4 & $90 Q 3-99 Q 1$ & B- & 2 \\
S.E. Asia & 34 & $89 Q 3-99 Q 1$ & A to B & 14 \\
Japan & 35 & $79 Q 1-99 Q 1$ & AAA to B+ & 14 \\
L. America & 14 & $89 Q 3-99 Q 1$ & A to B- & 5 \\
\hline Total & $\mathbf{2 4 3}$ & & - & $\mathbf{1 0 0}$ \\
\hline
\end{tabular}

1. Equity prices of companies in emerging markets are not available over the full sample period used for the estimation horizon of the GVAR. We have a complete series for all firms only for the U.S., U.K., Germany and Japan. For France, Italy and W. Europe, although some of the series go back through 1979Q1, data are available for all firms from 1987Q4 (France), 1987Q4 (Italy), 1989Q3 (W. Europe). For these regions the estimation of the multi-factor regressions are based on the available samples. For Latin America we have observations for all firms from 1990Q2.

2. The sample contains a mix of Moody's and S\&P ratings, although S\&P rating nomenclature is used for convenience. 
Table 2b

Portfolio Breakdown by Industry

\begin{tabular}{|l|c|}
\hline & $\#$ (\%) of Firms \\
\hline Agriculture, Mining \& Construction & $24(9.9 \%)$ \\
Communication, Electric \& Gas & $45(18.4 \%)$ \\
Durable Manufacturing & $30(12.3 \%)$ \\
Finance, Insurance \& Real Estate & $71(29.2 \%)$ \\
Non-Durable Manufacturing & $27(11.1 \%)$ \\
Service & $6(2.5 \%)$ \\
Wholesale \& Retail Trade & $40(16.4 \%)$ \\
\hline Total & $243(100 \%)$ \\
\hline
\end{tabular}


Table 3

Unconditional Default Probabilities by Rating

\begin{tabular}{|l|c|c|}
\hline \multicolumn{2}{|c|}{$1,2,3$ \& 4 quarter ahead (in basis points), exposure weighted in parentheses } \\
S\&P Rating & $\begin{array}{c}\text { Exposure } \\
\text { Share }\end{array}$ & $\hat{\pi}_{R}(T, T+4)$ \\
\hline AAA & $4.8 \%$ & $0.100(0.005)$ \\
AA & $17.6 \%$ & $0.372(0.066)$ \\
A & $32.5 \%$ & $0.721(0.234)$ \\
BBB & $27.7 \%$ & $10.69(2.97)$ \\
BB & $11.6 \%$ & $49.54(5.72)$ \\
B & $5.8 \%$ & $353.61(20.42)$ \\
\hline Portfolio & $100 \%$ & $\mathbf{2 9 . 4 2}$ \\
\hline
\end{tabular}

Based on ratings histories from S\&P, 1981Q1 - 1999Q1 
Table 4

Mean Group Estimates of Factor Loadings, Heterogeneous Model $\left(\mathbf{M}_{0}\right)$

\begin{tabular}{|l|c|c|c|}
\hline Factors & MGE & S.E. of MGE & t-ratios \\
& $\hat{\beta}$ & s.e. $(\hat{\beta})$ & \\
\hline constant & 0.022 & 0.002 & 10.495 \\
$\Delta \tilde{q}_{i, t+1}$ & 0.918 & 0.026 & 34.862 \\
$\Delta \rho_{i, t+1}$ & -2.990 & 0.528 & -5.663 \\
$\Delta p_{t+1}^{o}$ & 0.145 & 0.042 & 3.456 \\
\hline avg. $R^{2}$ & 0.238 & & \\
avg. $\bar{R}^{2}$ & 0.201 & & \\
$\#$ of firm quarters & 17,114 & & \\
\hline
\end{tabular}

$\Delta \tilde{q}_{i, t+1}$ is equal to $\Delta q_{i, t+1}$ (domestic equity return) or $\Delta q_{i, t+1}^{*}$ (foreign equity return), depending on which yields a better in-sample fit. $\Delta \rho_{i, t+1}$ is the change in the domestic interest rate, and $\Delta p_{t+1}^{o}$ is the change in oil prices. 
Table 5: Return Regression Results for Models $M_{1}-M_{4}$

\begin{tabular}{|c|c|c|c|c|c|c|c|c|c|c|c|c|c|c|c|c|c|c|c|}
\hline & \multirow{2}{*}{$\begin{array}{l}\mathbf{M}_{1} \text { : } \\
\text { Pooled }\end{array}$} & \multirow{2}{*}{$\begin{array}{l}M_{2}: \\
\text { Pooled + } \\
\text { Firm FE }\end{array}$} & \multicolumn{7}{|c|}{$M_{3}:$ Industry Fixed \& Marginal Effects } & \multicolumn{10}{|c|}{$\mathrm{M}_{4}$ :Region Fixed \& Marginal Effects } \\
\hline & & & 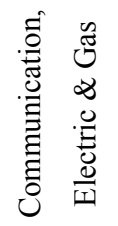 & 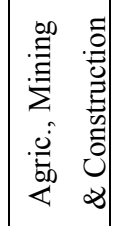 & 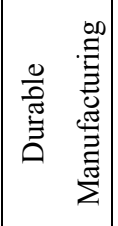 & 됨 & 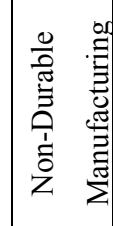 & $\frac{0}{0}$ & 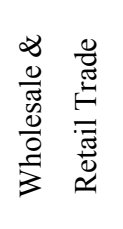 & $\dot{⿱ 宀 㠯}$ & 这 & 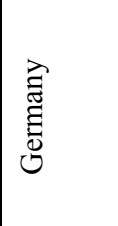 & 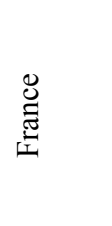 & $\frac{\lambda}{\Phi}$ & 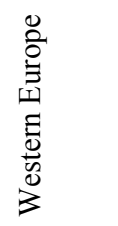 & 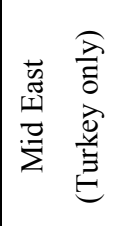 & 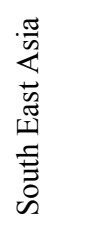 & $\begin{array}{l}\text { जี } \\
\text { : } \\
\text { Еิ }\end{array}$ & 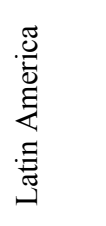 \\
\hline Constant & $\begin{array}{l}0.020^{* * *} \\
(0.001)\end{array}$ & & $\begin{array}{l}0.022^{* * *} \\
(0.003)\end{array}$ & $\begin{array}{l}0.014^{* * *} \\
(0.004)\end{array}$ & $\begin{array}{l}0.015^{* * *} \\
(0.004)\end{array}$ & $\begin{array}{l}0.023^{* * *} \\
(0.003)\end{array}$ & $\begin{array}{l}0.030^{* * *} \\
(0.004)\end{array}$ & $\begin{array}{l}0.028^{* * *} \\
(0.008)\end{array}$ & $\begin{array}{l}0.015^{* * *} \\
(0.003)\end{array}$ & $\begin{array}{l}0.015^{* * *} \\
(0.003)\end{array}$ & $\begin{array}{l}0.032^{* * *} \\
(0.004)\end{array}$ & $\begin{array}{c}0.006 \\
(0.004)\end{array}$ & $\begin{array}{l}0.020^{* * *} \\
(0.005)\end{array}$ & $\begin{array}{l}0.027^{* * *} \\
(0.006)\end{array}$ & $\begin{array}{l}0.026^{* * *} \\
(0.004)\end{array}$ & $\begin{array}{l}0.156^{* * *} \\
(0.014)\end{array}$ & $\begin{array}{l}0.012^{* * *} \\
(0.004)\end{array}$ & $\begin{array}{l}0.008^{* * *} \\
(0.003)\end{array}$ & $\begin{array}{l}0.076^{* * *} \\
(0.007)\end{array}$ \\
\hline Equity & $\begin{array}{l}0.869^{* * *} \\
(0.016)\end{array}$ & $\begin{array}{l}0.865^{* * *} \\
(0.016)\end{array}$ & $\begin{array}{l}0.752^{* * * *} \\
(0.081)\end{array}$ & $\begin{array}{l}0.889^{* * *} \\
(0.051)\end{array}$ & $\begin{array}{l}0.834^{* * * *} \\
(0.044)\end{array}$ & $\begin{array}{l}0.909^{* * * *} \\
(0.028)\end{array}$ & $\begin{array}{l}0.752^{* * *} \\
(0.055)\end{array}$ & $\begin{array}{l}0.775^{* * *} \\
(0.122)\end{array}$ & $\begin{array}{l}0.944^{* * *} \\
(0.045)\end{array}$ & $\begin{array}{l}0.916^{* * *} \\
(0.039)\end{array}$ & $\begin{array}{l}0.801^{* * *} \\
(0.065)\end{array}$ & $\begin{array}{l}1.165^{* * *} \\
(0.064)\end{array}$ & $\begin{array}{l}1.097^{* * * *} \\
(0.067)\end{array}$ & $\begin{array}{l}0.663^{* * *} \\
(0.059)\end{array}$ & $\begin{array}{l}0.808^{* * * *} \\
(0.056)\end{array}$ & $\begin{array}{l}1.926^{* * *} \\
(0.242)\end{array}$ & $\begin{array}{l}0.842^{* * * *} \\
(0.036)\end{array}$ & $\begin{array}{l}0.904^{* * *} \\
(0.044)\end{array}$ & $\begin{array}{l}0.622^{* * * *} \\
(0.045)\end{array}$ \\
\hline $\begin{array}{c}\text { Interest } \\
\text { rate }\end{array}$ & $\begin{array}{c}0.018 \\
(0.050)\end{array}$ & $\begin{array}{c}0.031 \\
(0.050)\end{array}$ & $\begin{array}{l}-0.020 \\
(0.081)\end{array}$ & $\begin{array}{c}0.115 \\
(0.106)\end{array}$ & $\begin{array}{c}0.124 \\
(0.082)\end{array}$ & $\begin{array}{c}-5.590^{* * *} \\
(0.573)\end{array}$ & $\begin{array}{l}3.402^{* *} \\
(1.515)\end{array}$ & $\begin{array}{l}-2.717 \\
(3.480)\end{array}$ & $\begin{array}{l}-3.711^{* * *} \\
(1.316)\end{array}$ & $\begin{array}{l}-5.974^{* * *} \\
(0.907)\end{array}$ & $\begin{array}{c}0.669 \\
(1.366)\end{array}$ & $\begin{array}{c}0.699 \\
(3.061)\end{array}$ & $\begin{array}{l}-1.016 \\
(2.414)\end{array}$ & $\begin{array}{l}-0.576 \\
(2.961)\end{array}$ & $\begin{array}{l}-2.493 \\
(2.288)\end{array}$ & $\begin{array}{l}-6.676^{* * *} \\
(0.840)\end{array}$ & $\begin{array}{l}-5.454^{* * *} \\
(0.824)\end{array}$ & $\begin{array}{l}-0.885 \\
(2.072)\end{array}$ & $\begin{array}{l}0.111^{* *} \\
(0.050)\end{array}$ \\
\hline Oil price & $\begin{array}{l}0.063^{* * *} \\
(0.021)\end{array}$ & $\begin{array}{l}0.064^{* * *} \\
(0.020)\end{array}$ & $\begin{array}{l}0.113^{* *} \\
(0.049)\end{array}$ & $\begin{array}{c}0.067 \\
(0.065)\end{array}$ & $\begin{array}{c}0.059 \\
(0.057)\end{array}$ & $\begin{array}{l}0.175^{* * *} \\
(0.040)\end{array}$ & $\begin{array}{c}0.012 \\
(0.059)\end{array}$ & $\begin{array}{c}0.058 \\
(0.124)\end{array}$ & $\begin{array}{l}-0.006 \\
(0.048)\end{array}$ & $\begin{array}{l}0.076^{* *} \\
(0.038)\end{array}$ & $\begin{array}{c}0.058 \\
(0.061)\end{array}$ & $\begin{array}{l}0.230^{* * * *} \\
(0.067)\end{array}$ & $\begin{array}{c}0.023 \\
(0.085)\end{array}$ & $\begin{array}{l}-0.004 \\
(0.104)\end{array}$ & $\begin{array}{l}-0.117 \\
(0.067)\end{array}$ & $\begin{array}{l}2.341^{* * *} \\
(0.241)\end{array}$ & $\begin{array}{c}0.047 \\
(0.066)\end{array}$ & $\begin{array}{c}0.009 \\
(0.053)\end{array}$ & $\begin{array}{l}1.035^{* * * *} \\
(0.125)\end{array}$ \\
\hline $\mathrm{R}^{2}$ & 0.144 & 0.160 & 0.152 & & & & & & & 0.173 & & & & & & & & & \\
\hline$\overline{\mathrm{R}}^{2}$ & 0.144 & 0.148 & 0.151 & & & & & & & 0.171 & & & & & & & & & \\
\hline $\begin{array}{l}\text { \# Firm } \\
\text { Quarters }\end{array}$ & 17,114 & 17,114 & 2,989 & 1,689 & 2,178 & 4,546 & 2,099 & 474 & 3,139 & 4,977 & 1,896 & 1,622 & 1,030 & 674 & 1,634 & 156 & 1,799 & 2,765 & 561 \\
\hline
\end{tabular}

() indicates the standard error of the parameter estimate

* indicates significance at the $10 \%$ level, $* *$ at the $5 \%$ level, and $* * *$ at the $1 \%$ level

Firm return regressions using quarterly returns for 243 firms from 21 countries grouped into 10 regions. More detail on the equity return data series by region is contained in Table 2a. Systematic risk factors are market equity return, "Equity," the change in the domestic (short) interest rate, "Interest rate," and the change in the (global) price of oil, "Oil price." The factor selection process and details on the return specifications for models $\mathrm{M}_{1}$ to $\mathrm{M}_{4}$ are given in Section 5.2. 
Table 6

\section{Baseline Scenario}

Statistics of Simulated Losses for Models $M_{0}-M_{4}$, One Year Ahead

Same $\lambda$

$\underline{\text { Value-at-Risk (VaR/EL) }}$

\begin{tabular}{|c|c|c|c|c|c|c|c|c|c|}
\hline Model & Specifications & EL & $\mathrm{UL}$ & $\mathrm{UL} / \mathrm{EL}$ & Skewness & Kurtosis & $99.0 \%$ & $99.5 \%$ & $99.9 \%$ \\
\hline $\mathrm{M}_{1 \mathrm{a}}$ & Homogeneous - No Rating & $0.001 \%$ & $0.030 \%$ & 20.8 & 29.4 & 1200 & $0 \%(0)$ & $0 \%(0)$ & $0.56 \%$ \\
\hline $\mathrm{M}_{1 \mathrm{~b}}$ & Homogeneous - w/ Rating & $0.002 \%$ & $0.035 \%$ & 17.1 & 22.1 & 633 & $0 \%(0)$ & $0 \%(0)$ & $0.62 \%(305)$ \\
\hline $\mathrm{M}_{2}$ & Firm fixed effects $\left(\sigma^{2}\right)$ & $0.002 \%$ & $0.030 \%$ & 19.4 & 23.9 & 691 & $0 \%(0)$ & $0 \%(0)$ & $0.59 \%(377)$ \\
\hline $\mathrm{M}_{3}$ & Industry $\left(\sigma_{\mathrm{s}}^{2}\right)$ & $0.006 \%$ & $0.062 \%$ & 10.7 & 12.9 & 194 & $0.15 \%(26)$ & $0.53 \%(92)$ & $0.88 \%(153)$ \\
\hline $\mathrm{M}_{4}$ & Regional $\left(\sigma_{i}^{2}\right)$ & $0.023 \%$ & $0.120 \%$ & 5.2 & 6.5 & 56 & $0.63 \%(27)$ & $0.85 \%(37)$ & $1.25 \%(54)$ \\
\hline $\mathrm{M}_{0}$ & Heterogeneous $\left(\sigma_{\text {jis }}^{2}\right)$ & $0.094 \%$ & $0.239 \%$ & 2.5 & 3.6 & 24 & $1.06 \%(11)$ & $1.33 \%(14)$ & $1.93 \%(21)$ \\
\hline
\end{tabular}

Same DD $\quad$ Value-at-Risk (VaR/EL)

\begin{tabular}{|c|c|c|c|c|c|c|c|c|c|}
\hline Model & Specifications & $\mathrm{EL}$ & $\mathrm{UL}$ & $\mathrm{UL} / \mathrm{EL}$ & Skewness & Kurtosis & $99.0 \%$ & $99.5 \%$ & $99.9 \%$ \\
\hline $\mathrm{M}_{1 \mathrm{a}}$ & Homogeneous - No Rating & $0.644 \%$ & $0.905 \%$ & 1.4 & 2.9 & 19 & $4.16 \%(6)$ & $5.07 \%(8)$ & $7.31 \%(11)$ \\
\hline $\mathrm{M}_{1 \mathrm{~b}}$ & Homogeneous - w/ Rating & $0.150 \%$ & $0.363 \%$ & 2.4 & 4.3 & 36 & $1.63 \%(11)$ & $2.08 \%(14)$ & $3.27 \%(22)$ \\
\hline $\mathrm{M}_{2}$ & Firm fixed effects $\left(\sigma^{2}\right)$ & $0.131 \%$ & $0.324 \%$ & 2.5 & 4.3 & 36 & $1.47 \%(11)$ & $1.84 \%(14)$ & $2.91 \%(22)$ \\
\hline $\mathrm{M}_{3}$ & Industry $\left(\sigma_{\mathrm{s}}^{2}\right)$ & $0.146 \%$ & $0.358 \%$ & 2.5 & 4.2 & 34 & $1.63 \%(11)$ & $2.06 \%(14)$ & $3.16 \%(22)$ \\
\hline $\mathrm{M}_{4}$ & Regional $\left(\sigma_{i}^{2}\right)$ & $0.152 \%$ & $0.358 \%$ & 2.4 & 3.8 & 27 & $1.62 \%(11)$ & $2.01 \%(13)$ & $2.96 \%$ \\
\hline $\mathrm{M}_{0}$ & Heterogeneous $\left(\sigma_{\mathrm{jis}}^{2}\right)$ & $0.086 \%$ & $0.259 \%$ & 3.0 & 5.4 & 58 & $1.18 \%(14)$ & $1.52 \%(18)$ & $2.43 \%(28)$ \\
\hline
\end{tabular}

Simulated one year ahead loss distributions for all return model specifications using 200,000 simulations. Details on the return specifications for models $\mathrm{M}_{0}$ to $\mathrm{M}_{4}$ are given in Section 5.2. Table compares two alternative identification restrictions: top panel imposes the same return default threshold, $\lambda$, by rating when rating information is used (this is the case for all models except $\mathrm{M}_{1 \mathrm{a}}$ ), while bottom panel imposes the same distance to default, DD, by rating when rating information is used. 
Table 7

$\pm 2.33 \sigma$ Shock to U.S. Real Equity Returns

Statistics of Simulated Losses for Models $\mathbf{M}_{0}-\mathbf{M}_{4}$, One Year Ahead, Same $\lambda$

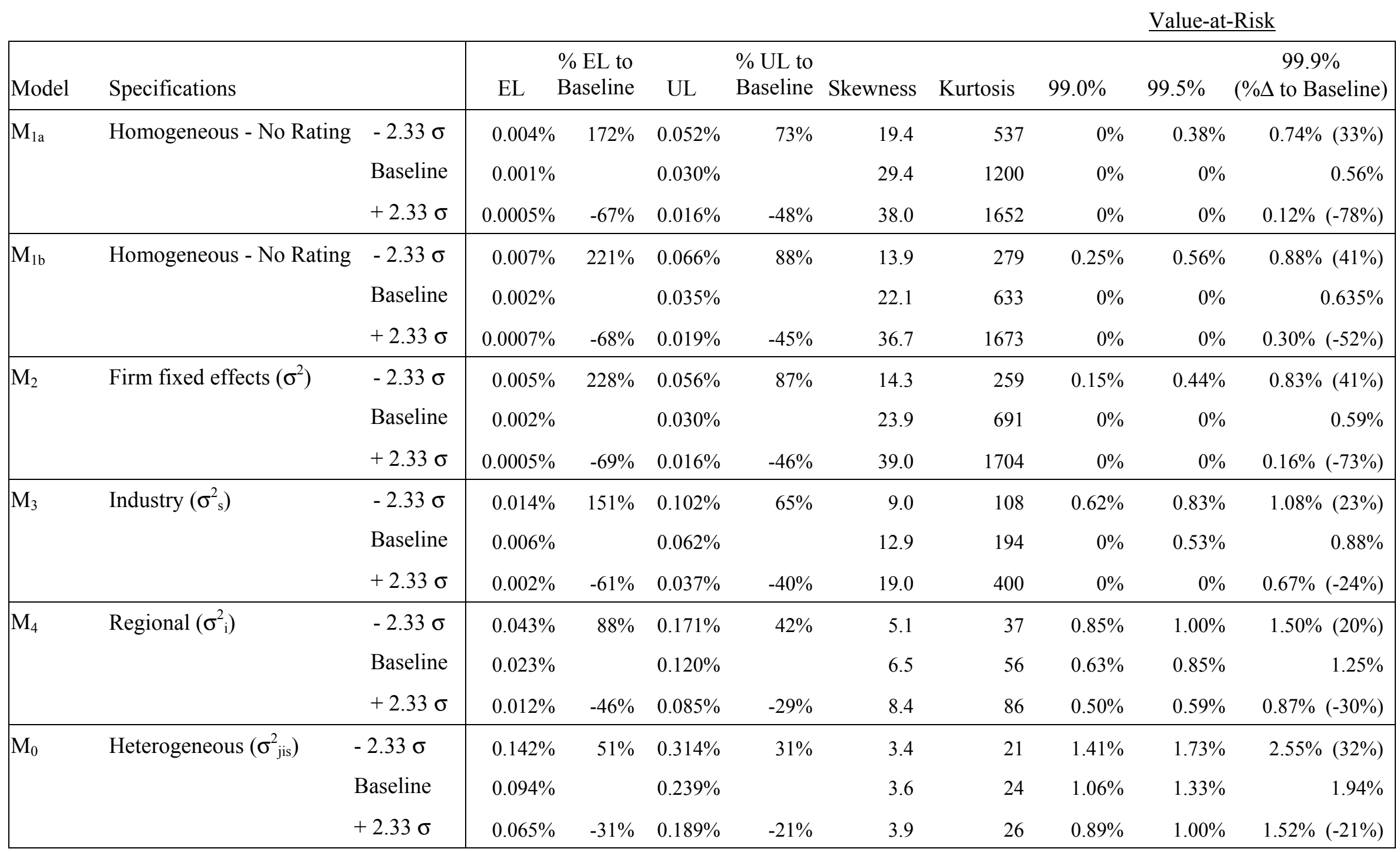

Simulated one year ahead loss distributions for all return model specifications imposing symmetric shocks to U.S. market equity returns. 200,000 simulations are used, and the same return default threshold, $\lambda$, by rating when rating information is used (this is the case for all models except $\mathrm{M}_{1 \mathrm{a}}$ ) is imposed. 
Table 8

+2.33 $\sigma$ Shock to German Interest Rates: Quarterly Increase of $0.33 \%$

Statistics of Simulated Losses for Models $\mathbf{M}_{0}-\mathbf{M}_{4}$, One Year Ahead, same $\lambda$

$\underline{\text { Value-at-Risk }}$

\begin{tabular}{|c|c|c|c|c|c|c|c|c|c|c|}
\hline Model & Specifications & EL & $\begin{array}{l}\% \Delta \text { EL to } \\
\text { Baseline }\end{array}$ & UL & $\begin{array}{l}\% \Delta \text { UL to } \\
\text { Baseline }\end{array}$ & Skewness & Kurtosis & $99.0 \%$ & $99.5 \%$ & $\begin{array}{c}99.9 \% \\
(\% \Delta \text { to Baseline })\end{array}$ \\
\hline $\mathrm{M}_{1 \mathrm{a}}$ & Homogeneous - No Rating & $0.002 \%$ & $39 \%$ & $0.036 \%$ & $20 \%$ & 26.2 & 980 & $0 \%$ & $0 \%$ & $0.58 \%(5 \%)$ \\
\hline $\mathrm{M}_{1 \mathrm{~b}}$ & Homogeneous - w/ Rating & $0.003 \%$ & $32 \%$ & $0.041 \%$ & $16 \%$ & 19.7 & 511 & $0 \%$ & $0.180 \%$ & $0.65 \%(4 \%)$ \\
\hline $\mathrm{M}_{2}$ & Firm fixed effects $\left(\sigma^{2}\right)$ & $0.002 \%$ & $28 \%$ & $0.034 \%$ & $13 \%$ & 20.8 & 520 & $0 \%$ & $0 \%$ & $0.59 \%(1 \%)$ \\
\hline $\mathrm{M}_{3}$ & Industry $\left(\sigma_{\mathrm{s}}^{2}\right)$ & $0.007 \%$ & $22 \%$ & $0.068 \%$ & $10 \%$ & 11.7 & 164 & $0.33 \%$ & $0.56 \%$ & $0.88 \%(<1 \%)$ \\
\hline $\mathrm{M}_{4}$ & Regional $\left(\sigma_{i}^{2}\right)$ & $0.026 \%$ & $15 \%$ & $0.130 \%$ & $8 \%$ & 6.2 & 51 & $0.77 \%$ & $0.85 \%$ & $1.34 \%(7 \%)$ \\
\hline $\mathrm{M}_{0}$ & Heterogeneous $\left(\sigma_{\mathrm{jis}}^{2}\right)$ & $0.10 \%$ & $8 \%$ & $0.25 \%$ & $5 \%$ & 3.6 & 23 & $1.11 \%$ & $1.40 \%$ & $2.04(5 \%)$ \\
\hline
\end{tabular}

Simulated one year ahead loss distributions for all return model specifications imposing an adverse shock to the German short maturity interest rate. 200,000 simulations are used, and the same return default threshold, $\lambda$, by rating when rating information is used (this is the case for all models except $\left.\mathrm{M}_{\mathrm{la}}\right)$ is imposed. 
Table 9

\section{$-2.33 \sigma$ Shock to U.S. Real Output: Quarterly Decline of $1.85 \%$}

Statistics of Simulated Losses for Models $M_{0}-M_{4}$, One Year Ahead, same $\lambda$

Value-at-Risk

\begin{tabular}{|c|c|c|c|c|c|c|c|c|c|c|}
\hline Model & Specifications & EL & $\begin{array}{l}\% \Delta \text { EL to } \\
\text { Baseline }\end{array}$ & UL & $\begin{array}{l}\% \Delta \text { UL to } \\
\text { Baseline }\end{array}$ & Skewness & Kurtosis & $99.0 \%$ & $99.5 \%$ & $\begin{array}{c}99.9 \% \\
(\% \Delta \text { to Baseline })\end{array}$ \\
\hline $\mathrm{M}_{1 \mathrm{a}}$ & Homogeneous - No Rating & $0.001 \%$ & $-13 \%$ & $0.028 \%$ & $-6 \%$ & 31.8 & 1405 & $0 \%$ & $0 \%$ & $0.53 \%(-4 \%)$ \\
\hline $\mathrm{M}_{1 \mathrm{~b}}$ & Homogeneous - w/ Rating & $0.002 \%$ & $-2 \%$ & $0.035 \%$ & $0 \%$ & 22.2 & 619 & $0 \%$ & $0 \%$ & $0.63 \%(<1 \%)$ \\
\hline $\mathrm{M}_{2}$ & Firm fixed effects $\left(\sigma^{2}\right)$ & $0.001 \%$ & $-4 \%$ & $0.030 \%$ & $-2 \%$ & 24.3 & 703 & $0 \%$ & $0 \%$ & $0.59(<1 \%)$ \\
\hline $\mathrm{M}_{3}$ & Industry $\left(\sigma_{\mathrm{s}}^{2}\right)$ & $0.006 \%$ & $-2 \%$ & $0.062 \%$ & $0 \%$ & 12.9 & 192 & $0.15 \%$ & $0.53 \%$ & $0.88 \%(<1 \%)$ \\
\hline $\mathrm{M}_{4}$ & Regional $\left(\sigma_{i}^{2}\right)$ & $0.022 \%$ & $-6 \%$ & $0.117 \%$ & $-3 \%$ & 6.7 & 59 & $0.59 \%$ & $0.85 \%$ & $1.23 \%(-2 \%)$ \\
\hline $\mathrm{M}_{0}$ & Heterogeneous $\left(\sigma_{\text {jis }}^{2}\right)$ & $0.088 \%$ & $-7 \%$ & $0.230 \%$ & $-4 \%$ & 3.7 & 24 & $1.00 \%$ & $1.28 \%$ & $1.86 \%(-4 \%)$ \\
\hline
\end{tabular}

Simulated one year ahead loss distributions for all return model specifications imposing an adverse shock to U.S. real output growth. 200,000 simulations are used, and the same return default threshold, $\lambda$, by rating when rating information is used (this is the case for all models except $\mathrm{M}_{1 \mathrm{a}}$ ) is imposed. 
Table 10

Extreme Shocks to Real U.S. Equity Returns

Statistics of Simulated Losses for Models $\mathbf{M}_{0}-\mathbf{M}_{4}$, One Year Ahead, same $\lambda$

Panel A: $-5 \sigma$, Quarterly Decline of $30.6 \%$

Value-at-Risk

\begin{tabular}{|c|c|c|c|c|c|c|c|c|c|c|}
\hline Model & Specifications & EL & $\begin{array}{l}\% \Delta \text { EL to } \\
\text { Baseline }\end{array}$ & UL & $\begin{array}{l}\% \Delta \text { UL to } \\
\text { Baseline }\end{array}$ & Skewness & Kurtosis & $99.0 \%$ & $99.5 \%$ & $\begin{array}{c}99.9 \% \\
(\% \Delta \text { to Baseline) }\end{array}$ \\
\hline $\mathrm{M}_{1 \mathrm{a}}$ & Homogeneous - No Rating & $0.01 \%$ & $794 \%$ & $0.10 \%$ & $244 \%$ & 12.7 & 241 & $0.53 \%$ & $0.64 \%$ & $1.39 \%(150 \%)$ \\
\hline $\mathrm{M}_{1 \mathrm{~b}}$ & Homogeneous - w/ Rating & $0.02 \%$ & $963 \%$ & $0.13 \%$ & $265 \%$ & 8.8 & 116 & $0.64 \%$ & $0.88 \%$ & $1.47 \%(135 \%)$ \\
\hline $\mathrm{M}_{2}$ & Firm fixed effects $\left(\sigma^{2}\right)$ & $0.02 \%$ & $1035 \%$ & $0.11 \%$ & $266 \%$ & 8.8 & 113 & $0.62 \%$ & $0.76 \%$ & $1.22 \%(107 \%)$ \\
\hline $\mathrm{M}_{3}$ & Industry $\left(\sigma_{\mathrm{s}}^{2}\right)$ & $0.04 \%$ & $588 \%$ & $0.18 \%$ & $192 \%$ & 6.3 & 59 & $0.88 \%$ & $1.08 \%$ & $1.77 \%(101 \%$ \\
\hline $\mathrm{M}_{4}$ & $\operatorname{Regional}\left(\sigma_{\mathrm{i}}^{2}\right)$ & $0.09 \%$ & $275 \%$ & $0.26 \%$ & $113 \%$ & 4.1 & 27 & $1.20 \%$ & $1.43 \%$ & $2.15 \%(72 \%)$ \\
\hline $\mathrm{M}_{0}$ & Heterogeneous $\left(\sigma_{\mathrm{jis}}^{2}\right)$ & $0.24 \%$ & $154 \%$ & $0.44 \%$ & $85 \%$ & 3.1 & 19 & $1.98 \%$ & $2.42 \%$ & $3.53 \%(83 \%)$ \\
\hline
\end{tabular}

Panel B: $\quad-8.02 \sigma$, Quarterly Decline of $49 \%$

Value-at-Risk

\begin{tabular}{|c|c|c|c|c|c|c|c|c|c|c|}
\hline Model & Specifications & EL & $\begin{array}{l}\% \Delta \text { EL to } \\
\text { Baseline }\end{array}$ & UL & $\begin{array}{l}\% \Delta \text { UL to } \\
\text { Baseline }\end{array}$ & Skewness & Kurtosis & $99.0 \%$ & $99.5 \%$ & $\begin{array}{c}99.9 \% \\
(\% \Delta \text { to Baseline) }\end{array}$ \\
\hline $\mathrm{M}_{1 \mathrm{a}}$ & Homogeneous - No Rating & $0.05 \%$ & $3363 \%$ & $0.23 \%$ & $674 \%$ & 8.5 & 119 & $1.17 \%$ & $1.54 \%$ & $2.72 \%(390 \%)$ \\
\hline $\mathrm{M}_{1 \mathrm{~b}}$ & Homogeneous - w/ Rating & $0.08 \%$ & $3914 \%$ & $0.28 \%$ & $689 \%$ & 5.7 & 57 & $1.29 \%$ & $1.67 \%$ & $2.79 \%(347 \%)$ \\
\hline $\mathrm{M}_{2}$ & Firm fixed effects $\left(\sigma^{2}\right)$ & $0.07 \%$ & $4203 \%$ & $0.24 \%$ & $687 \%$ & 5.7 & 55 & $1.08 \%$ & $1.44 \%$ & $2.36 \%(302 \%)$ \\
\hline $\mathrm{M}_{3}$ & Industry $\left(\sigma_{\mathrm{s}}^{2}\right)$ & $0.12 \%$ & $1974 \%$ & $0.35 \%$ & $460 \%$ & 4.4 & 32 & $1.63 \%$ & $1.98 \%$ & $3.07 \%(249 \%)$ \\
\hline $\mathrm{M}_{4}$ & Regional $\left(\sigma_{i}^{2}\right)$ & $0.19 \%$ & $714 \%$ & $0.41 \%$ & $242 \%$ & 3.4 & 20 & $1.86 \%$ & $2.24 \%$ & $3.32 \%(165 \%)$ \\
\hline $\mathrm{M}_{0}$ & Heterogeneous $\left(\sigma_{\mathrm{jis}}^{2}\right)$ & $0.45 \%$ & $382 \%$ & $0.69 \%$ & $187 \%$ & 2.9 & 19 & $3.09 \%$ & $3.74 \%$ & $5.44 \%(181 \%)$ \\
\hline
\end{tabular}

Simulated one year ahead loss distributions for all return model specifications imposing two more extreme adverse shocks to U.S. U.S. market equity returns . 200,000 simulations are used, and the same return default threshold, $\lambda$, by rating when rating information is used (this is the case for all models except $\mathrm{M}_{1 \mathrm{a}}$ ) is imposed. 
Table 11

Mean Group Estimates of Factor Loadings, Heterogeneous Model ( $\left.\mathbf{M}_{0 \mathrm{~b}}\right)$

Alternative specification

\begin{tabular}{|l|c|c|c|}
\hline Factors & MGE & S.E. of MGE & t-ratios \\
& $\hat{\beta}$ & s.e. $(\hat{\beta})$ & \\
\hline constant & 0.010 & 0.003 & 3.075 \\
$\Delta \bar{q}_{t+1}$ & 0.780 & 0.031 & 24.874 \\
$\Delta \rho_{i, t+1}$ & -4.326 & 0.520 & -6.923 \\
$\Delta p_{t+1}^{o}$ & 0.041 & 0.038 & 1.064 \\
$\Delta y_{i, t+1}$ & 0.700 & 0.260 & 2.695 \\
\hline avg. $R^{2}$ & 0.157 & & \\
avg. $\bar{R}^{2}$ & 0.103 & & \\
$\#$ of firm quarters & 17,114 & & \\
\hline
\end{tabular}

$\Delta \bar{q}_{t+1}$ is the cross-sectional average of all equity indices in the GVAR model using 1996 PPP weights, $\Delta \rho_{i, t+1}$ is the change in the domestic interest rate, $\Delta p_{t+1}^{o}$ is the change in oil prices and $\Delta y_{i, t+1}$ is the change in domestic real GDP. 
Table 12

Impact of Various 2.33 $\sigma$ Shocks to on Alternative Model

Statistics of Simulated Losses, One Year Ahead, same $\lambda$

$\underline{\text { Value-at-Risk }}$

\begin{tabular}{|c|c|c|c|c|c|c|c|c|c|}
\hline Scenario & EL & $\begin{array}{l}\% \Delta \text { EL to } \\
\text { Baseline }\end{array}$ & $\mathrm{UL}$ & $\begin{array}{l}\% \Delta \mathrm{UL} \text { to } \\
\text { Baseline }\end{array}$ & Skewness & Kurtosis & $99.0 \%$ & $99.5 \%$ & $\begin{array}{c}99.9 \% \\
(\% \Delta \text { to Baseline })\end{array}$ \\
\hline Baseline & $0.091 \%$ & & $0.208 \%$ & & 2.7 & 12 & $0.92 \%$ & $1.00 \%$ & $1.43 \%$ \\
\hline$-2.33 \sigma$ shock to U.S. real output growth & $0.090 \%$ & $-1 \%$ & $0.205 \%$ & $-2 \%$ & 2.6 & 11 & $0.91 \%$ & $0.97 \%$ & $1.39 \%(-3 \%)$ \\
\hline$+2.33 \sigma$ shock to German interest rates & $0.097 \%$ & $6 \%$ & $0.215 \%$ & $4 \%$ & 2.7 & 12 & $0.94 \%$ & $1.07 \%$ & $1.52 \%(6 \%)$ \\
\hline$-2.33 \sigma$ shock to U.S. equity returns & $0.137 \%$ & $51 \%$ & $0.259 \%$ & $25 \%$ & 2.3 & 10 & $1.08 \%$ & $1.26 \%$ & $1.74 \%(22 \%)$ \\
\hline$+2.33 \sigma$ shock to U.S. equity returns & $0.066 \%$ & $-28 \%$ & $0.176 \%$ & $-15 \%$ & 3.1 & 15 & $0.79 \%$ & $0.94 \%$ & $1.28 \%(-11 \%)$ \\
\hline
\end{tabular}

Simulated one year ahead loss distributions using the alternative specification of the fully heterogeneous model $\mathrm{M}_{0}$, described in Section 6.4. Comparing loss distributions for the baseline scenario, adverse shocks to U.S. real output growth and German short maturity interest rates, and symmetric shocks to U.S. equity returns. For all scenarios, 200,000 simulations are used, and the same return default threshold, $\lambda$, by rating when rating information is used (this is the case for all models except $\mathrm{M}_{1 \mathrm{a}}$ ) is imposed. 
Table 13

Impact of Granularity using Vasicek model

\begin{tabular}{|l|c|c|c|c|c|}
\cline { 2 - 6 } \multicolumn{1}{c|}{} & \multicolumn{5}{c|}{ \# of loans in portfolio (N) } \\
& 119 & 243 & 1,000 & 5,000 & 10,000 \\
\hline Deviation from asymptotic lower bound & $80 \%$ & $44 \%$ & $12 \%$ & $3 \%$ & $2 \%$ \\
\hline
\end{tabular}




\section{One-Year Unconditional and Conditional PDs (same $\lambda$ )}

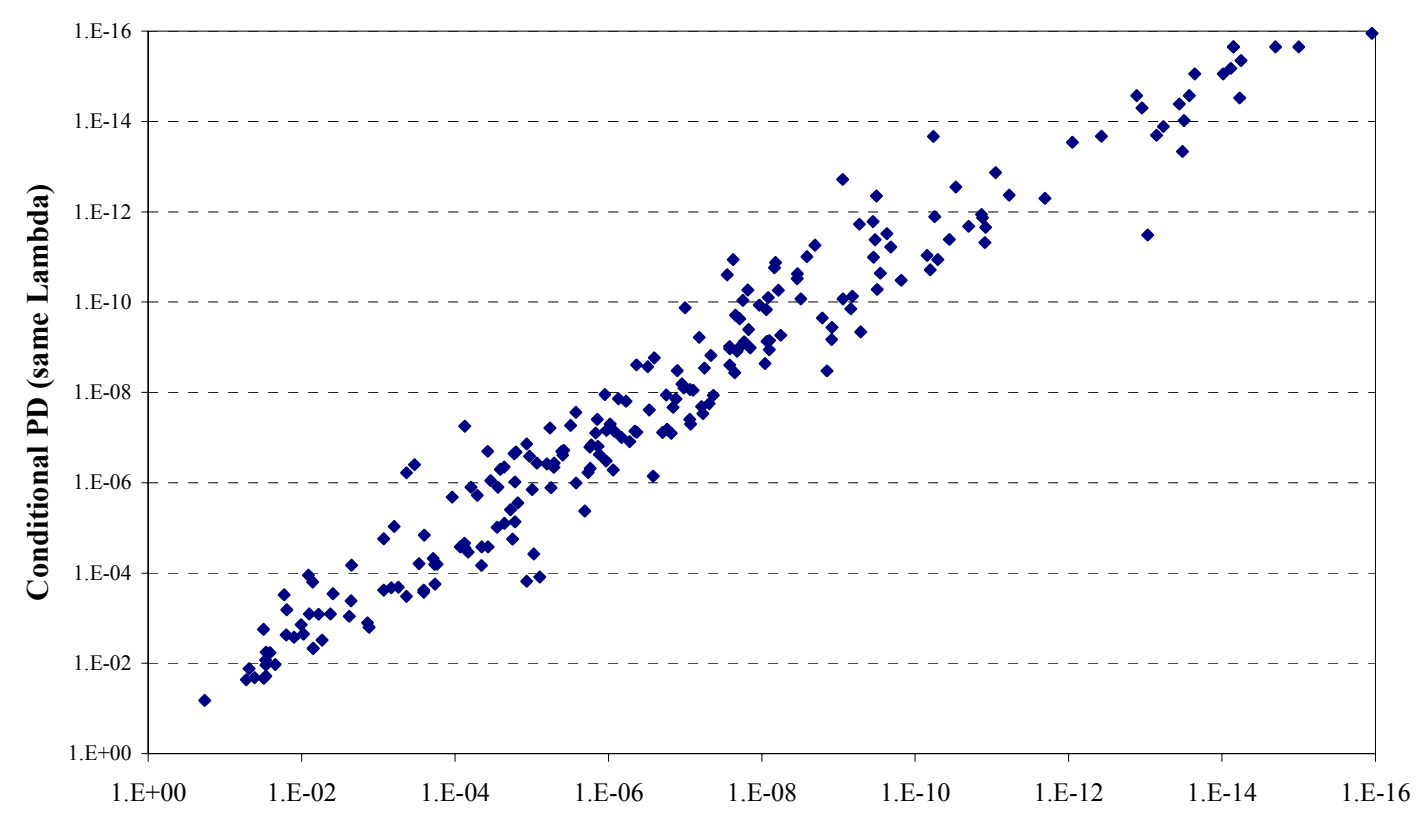

Unconditional PD (same lambda)

One Year Unconditional and Conditional PDs (same DD)

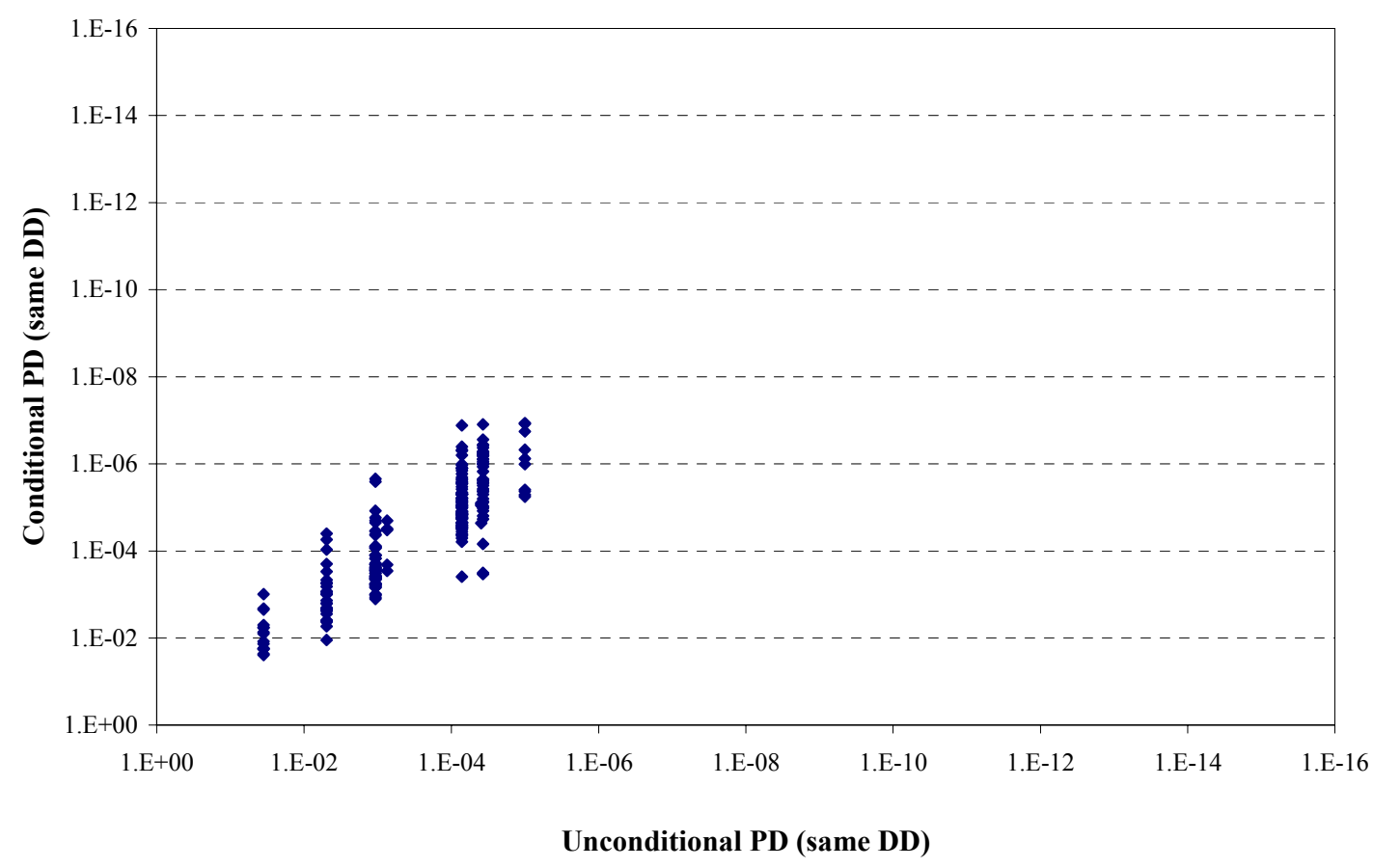

Figure 1: Scatter plot of unconditional (horizontal axis) and conditional (vertical axis) one-year probabilities of default $(P D)$ for 243 firms in portfolio. Top panel: same default threshold $(\lambda)$ by credit rating for all firms. Bottom panel: same distance to default $(D D)$ by credit rating for all firms. 

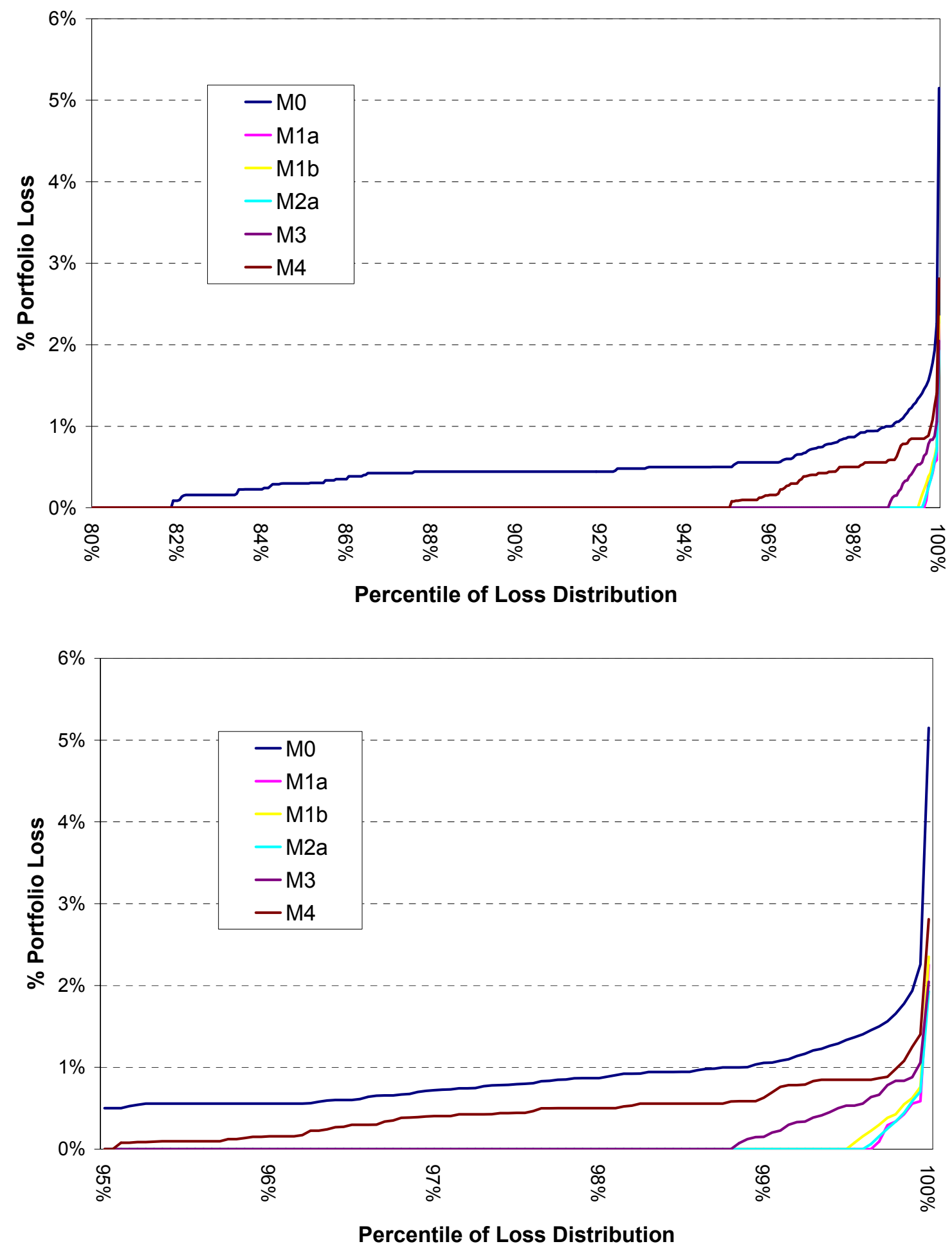

Figure 2: Comparing the tail of the baseline loss distributions across models, same $\lambda$ identifying restriction by rating when rating information is used, 200,000 simulations. Top panel: $20 \%$ tail (losses beyond the $80^{\text {th }}$ percentile). Bottom panel: $5 \%$ tail (losses beyond the $95^{\text {th }}$ percentile). Model $\mathrm{M}_{0}$ is fully heterogeneous model, $\mathrm{M}_{1 \mathrm{a}}$ is homogenous (no rating information), $\mathrm{M}_{1 \mathrm{~b}}$ is homogeneous (with rating information), $\mathrm{M}_{2}$ is firm fixed effects, $\mathrm{M}_{3}$ is industry fixed and marginal effects, and $\mathrm{M}_{4}$ is regional fixed and marginal effects. 

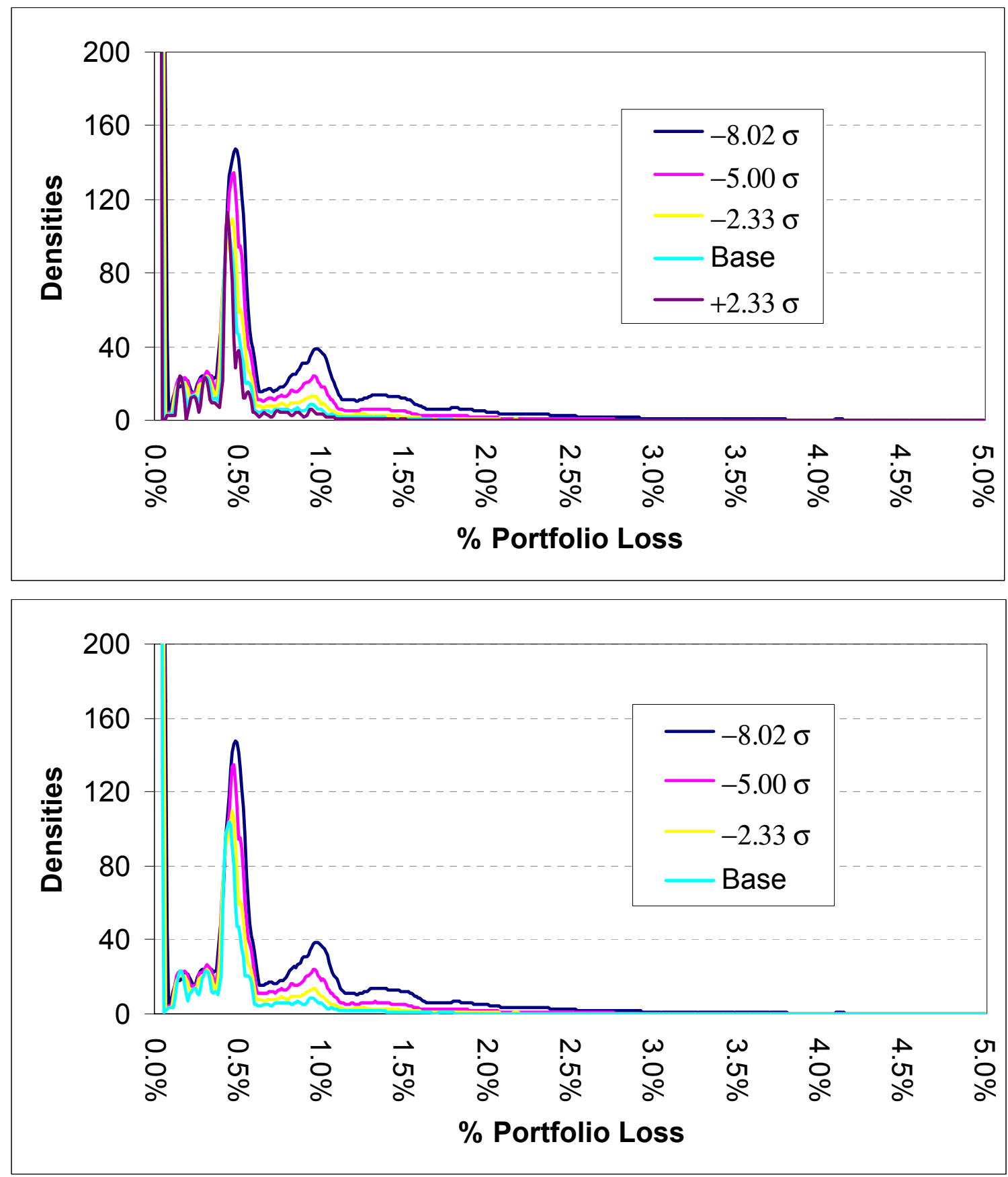

Figure 3: Comparing simulated loss densities across different shocks to U.S. real equity prices, fully heterogeneous model $\mathrm{M}_{0}$ imposing the same default threshold $\lambda$ identifying condition, 200,000 simulations. All densities are estimated with an Epanechnikov kernel using Silverman's (1986) optimal bandwidth. 